Document downloaded from:

http://hdl.handle.net/10251/163203

This paper must be cited as:

Torregrosa, AJ.; García-Cuevas González, LM.; Inhestern, LB.; Soler-Blanco, P. (2021). Radial turbine sound and noise characterisation with acoustic transfer matrices by means of fast one-dimensional models. International Journal of Engine Research. 22(4):1312-1328. https://doi.org/10.1177/1468087419889429

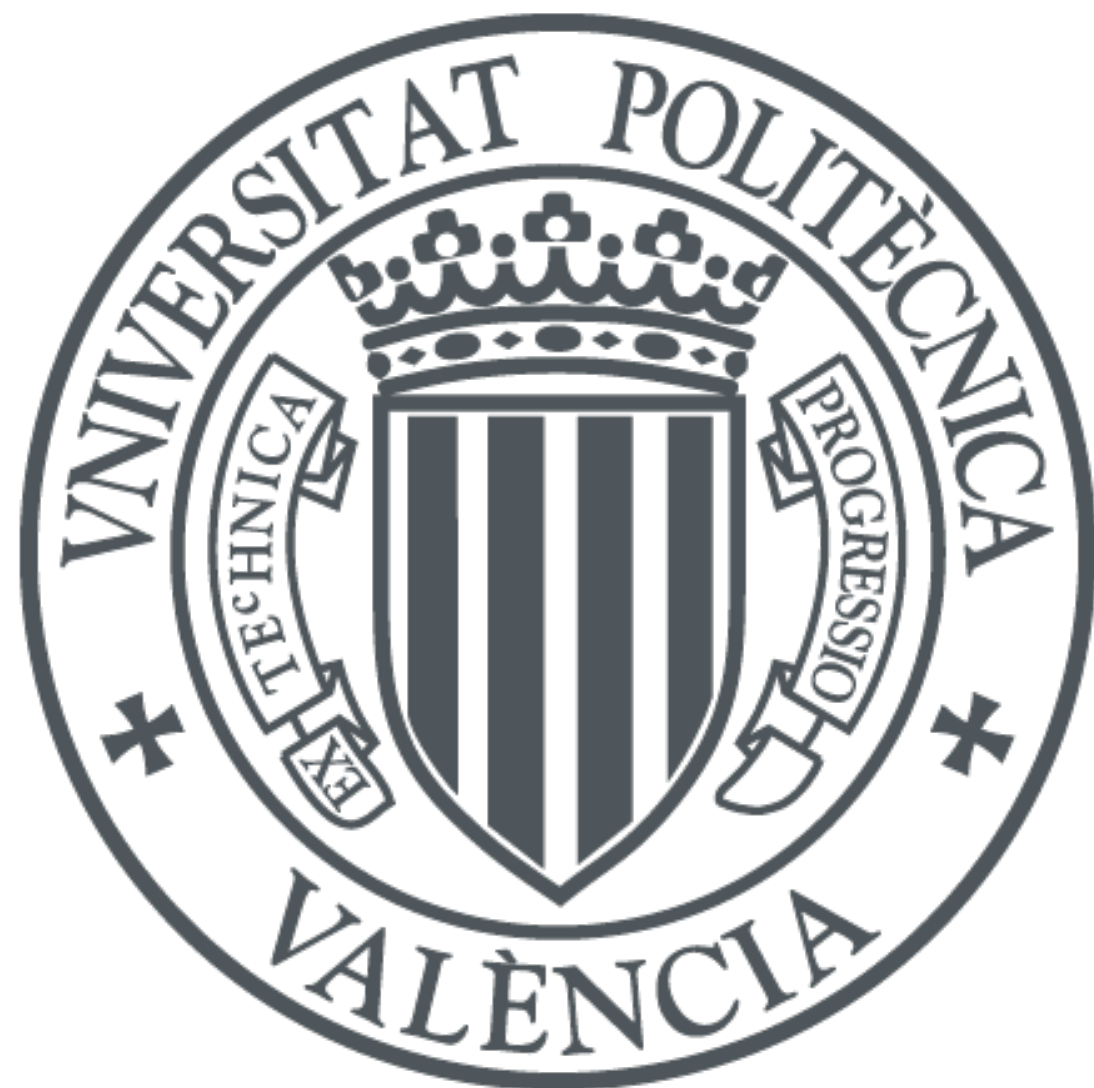

The final publication is available at

https://doi.org/10.1177/1468087419889429

Copyright SAGE Publications

Additional Information

This is the author's version of a work that was accepted for publication in International Journal of Engine Research. Changes resulting from the publishing process, such as peer review, editing, corrections, structural formatting, and other quality control mechanisms may not be reflected in this document. Changes may have been made to this work since it was submitted for publication. A definitive version was subsequently published as https://doi.org/10.1177/1468087419889429. 


\title{
Radial Turbine Sound and Noise Characterisation with Acoustic Transfer Matrices by means of Fast One-Dimensional Models
}

\author{
A. Torregrosa ${ }^{1}$, L.M. García-Cuevas ${ }^{1}$,L.B. Inhestern ${ }^{1}$, and P. Soler ${ }^{1}$
}

\begin{abstract}
Estimating correctly the turbine acoustics can be valuable during the engine design stage, in fact, it can lead to a more optimized design of the silencer and aftertreatment, as well as a to better prediction of the scavenging effects. However, obtaining the sound and noise emissions of radial turbocharger turbines with low computational costs can be challenging. To consider these effects in a time-efficient manner, the acoustic response of single entry radial turbines can be characterised by means of acoustic transfer matrices that change with the operating conditions. Exploiting the different time-scales of the acoustic phenomena and the change in the operating point of the turbine, lookup tables of acoustic transfer matrices can be computed. Following, the obtained characterisation can be used in mean value engine models. This paper presents a method for generating these lookup tables by means of fast one-dimensional simulations of thoroughly validated fidelity, both in terms of acoustics and of extrapolation capabilities. Due to the inherent behaviour of radial turbines, the number of computations needed to fill the lookup tables is relatively small, so the method can be used as a simple preprocessing phase before mean-value simulation campaigns.
\end{abstract}

\section{Keywords}

Turbocharger, Acoustic transfer matrix, One-dimensional model, Radial turbine, Noise, Transient flow

\section{Introduction}

The acoustic performance of radial turbochargers can be divided into passive and active categories[1]. In the compressor, active noise, including whoosh noise, is generated at a broad range of frequencies[2][3]. Also, the geometry of the elements directly upstream or at the inlet of the compressor affects its active noise characteristics, as shown by Broatch et al. [4] or Sharma et al.[5] In the turbine, sound and noise are actively generated at high frequencies and are associated with the rotation of the rotor blades, including rotating shock waves at high turbine expansion ratios. Passive acoustic properties influence the low frequency engine pulsations and are affected by the geometry of the turbine and its operating conditions. Experimental measurements to obtain these passive properties can be conducted as described in Peat et al.[6], i.e., producing pressure pulses at the turbine inlet by means of an electrovalve and measuring the oscillations in predefined points in the turbine inlet and outlet ducts, while maintaining an almost-constant rotational speed and mass flow. With some adaptations, higher amplitude pulses may be used [7], obtaining the backward- and forward-travelling pressure waves with beamforming arrays at both the turbine inlet and outlet ducts. This method has been also used and validated with radial compressors [8], demonstrating that a three-sensor-phased array beamforming technique is a very reliable method in the plane wave frequency range. Also twin-scroll turbines have been characterised experimentally under linear acoustic excitations[9], or even nonlinear acoustic excitations[10]. Those experimental characterisations may be prohibitive in a very broad range of operating conditions. However, the acoustic performance measurement provides very valuable information in order to develop and validate fast numerical models that may be used during engine development phases. High fidelity computational fluid dynamics (CFD) characterisations can provide valuable information, too. In the last five years, several studies about CFD characterisation of active noise generation in radial compressors can be found[2] [11][12]. The literature about CFD acoustic and noise characterisation of radial turbines has been scarce, nevertheless, some notable exceptions can be found such as the work by Marsan and Moreu[13].

The models for predicting the performance of radial turbines, including their behaviour in pulsating flow conditions, have evolved during the last decades as the computational resources have improved. From the early models proposed by Wallace et al [14] or Winterbone and Pearson[15] to the newest additions proposed by Hohenberg et al. [16], Zhanming et al. [17] or Piscaglia et al. [18], they tend to focus on performance parameters such as the instantaneous flow rate or torque. Even high-fidelity threedimensional simulations are routinely carried out in the present day, as in the work by Galindo et al.[19], where a radial turbine is simulated under pulsating flow conditions. Reasonably fast simulations are usually carried out with onedimensional discretisations of the geometry of the turbine, using equivalent tapered ducts for the turbine inlet, volute and outlet, as described by Costall et al. [20]. Some improvements can be achieved against this simplification without a big impact in computational costs by improving

\footnotetext{
${ }^{1}$ CMT - Motores Térmicos, Universitat Politècnica de València, ES
}

\section{Corresponding author:}

Luis Miguel García-Cuevas, CMT - Motores Térmicos, Universitat Politècnica de València, Camino de Vera, Valencia 46022, Spain

Email: luiga12@mot.upv.es 
the computation of the volute. The volute can be discretised as an one-dimensional tapered duct with a lateral connection to the vanes of the stator or the vaneless space before the rotor, dependending on the turbine stator characteristics [21] 22] [17]. It is also worth mentioning the difficulties in correlating turbine power with experiments as found in Avola et al. [23]

To the knowledge of the authors of this manuscript, the work focused in acoustic predictions has been limited, although there are some notable exceptions. Veloso et al. [24] propose an interesting approach for the modelling problem of the passive acoustic properties of radial turbines and compressors. In their work, they model the turbomachine as several one-dimensional tapered pipes connected together, with the rotor being a constricting pipe. The pressure and temperature drop in the turbine was set by means of PID controllers to match experimental data, and the transmission loss was computed and compared with experimental data at ten different operating conditions. The results were promising, but further developments were needed to use the method to predict the acoustic performance of turbines in operating points not already measured in experiments or in the turbine map. Galindo et al. [25] use a model proposed previously[22], which is similar to the one presented by Veloso et al.[24], for the main geometrical aspects of the turbine, while using simplified nozzles for the stator passages, conservation of rothalpy and mass flow for the rotor and a series of loss models. The results of the model are compared against a small set of experimental acoustic data, showing good agreement of the sound pressure level of the forward- and backward-travelling pressure waves in the frequency domain. The work of the present manuscript is based on the models presented by Galindo et al.[26], where their previous model[22] is adapted to use the work by Serrano et al. [27] to interpolate and extrapolate the turbine map in terms of adiabatic efficiency and mass flow. The frequency domain results showed good agreement against experimental data, with good capabilities to extrapolate to extreme off-design conditions.

This paper presents a method to exploit the prediction capabilities of a one-dimensional variable geometry turbine model in order to produce acoustic transfer matrices for arbitrary operating conditions. These matrices can be computed during a preprocessing phase prior to further extensive computation campaigns. Coupled with quasisteady calculations of the cycle-averaged turbine mass flow and efficiency, this method can be used to predict the turbine behaviour with an almost negligible computational cost. Other quasi-steady effects of the turbocharger can be easily taken into account, such as the compressor map extrapolation [28][29], the heat transfer [30][31][32] or the mechanical losses in the bearings [33].

\section{Method description}

In this section, the method to generate and use a lookup table of acoustic transfer matrices is presented. Firstly, the experimental campaign to obtain steady-state and pulsating flow turbine results is described. Secondly, the basis of the one-dimensional simulations used during the generation of the lookup tables is shown, and the procedure for generating them from these simulations is presented. Finally, a simple process to compute an interpolated acoustic transfer matrix (IATM) is proposed.

\subsection{Experimental campaign}

The experimental campaign has been carried out in the CMTMotores Térmicos gas stand for turbocharging research. This facility is specifically built for testing and measuring any type of automotive turbocharger under different conditions. In Figure 1, the configuration followed for the present work is presented.

The gas stand uses a screw compressor with a maximum flow rate of $0.2 \mathrm{~kg} \mathrm{~s}^{-1}$ at a maximum absolute pressure of $0.4 \mathrm{MPa}$. This screw compressor is used to feed the turbine (shown with the symbol $\mathrm{T}$ in Figure 1), and its flow rate is controlled by means of its rotational speed and a discharge valve. The air passes through a set of electrical heaters with an installed power of $40 \mathrm{~kW}$ to control its temperature up to $720 \mathrm{~K}$ at $0.2 \mathrm{~kg} \mathrm{~s}^{-1}$. When pulsating flow is required, a rotating valve (shown as RV) is placed after the electrical heaters, generating the desired pulses.

The turbocharger compressor (shown as C) is used as a brake during the characterisation. In order to control its braking torque, a backpressure valve is placed downstream of it. The compressor side of the gas stand can be operated in closed-loop, pressurising the flow and allowing the measurement of the turbine in a wider operating range. All the flow that passes through the compressor also passes through filters and a water-air heat exchanger.

An independent lubrication system (ILS) is used for the turbocharger. Both the oil pressure and temperature were controlled during the tests. An independent cooling system (ICS) was also present, although it was not used during the tests.

The mass flow of the compressor and turbine were measured by means of hot film flow meters (shown with the symbol $\dot{m}$ in Figure 1), placed after filters and heat exchangers. The flow temperature (shown with the symbol $T$ ) was measured by four type $\mathrm{K}$ thermocouples at the turbine inlet, turbine outlet, compressor inlet and compressor outlet. The average air pressure was measured by means of piezoresistive transmitters (shown as $p$ ) in the same stations as the flow temperature. The rotational speed of the turbocharger was measured by means of an induced currents transducer placed inside the compressor casing. To monitor the turbine stator vanes position, an induction displacement sensor was used, measuring from fully closed $(0 \%)$ to fully opened $(100 \%)$. Finally, an array of three piezoelectric transducers was placed at the turbine inlet and another one at the turbine outlet (shown as BF), 10 diameters away of it, with a distance between sensors of one diameter (around $50 \mathrm{~mm}$ ). These arrays were used during the pulsating flow characterisation campaign to get, via beamforming [34], the pressure pulses travelling downstream and upstream. All the sensors were installed according to Society of Automotive Engineers (SAE) J1723 and J1826 standards [35, 36], ensuring flow development. The details of the sensors are shown in Table 1 .

The experiments used in this work were done in quasiadiabatic conditions, minimising the internal and external heat flows. The ducts and the turbocharger were thermally 


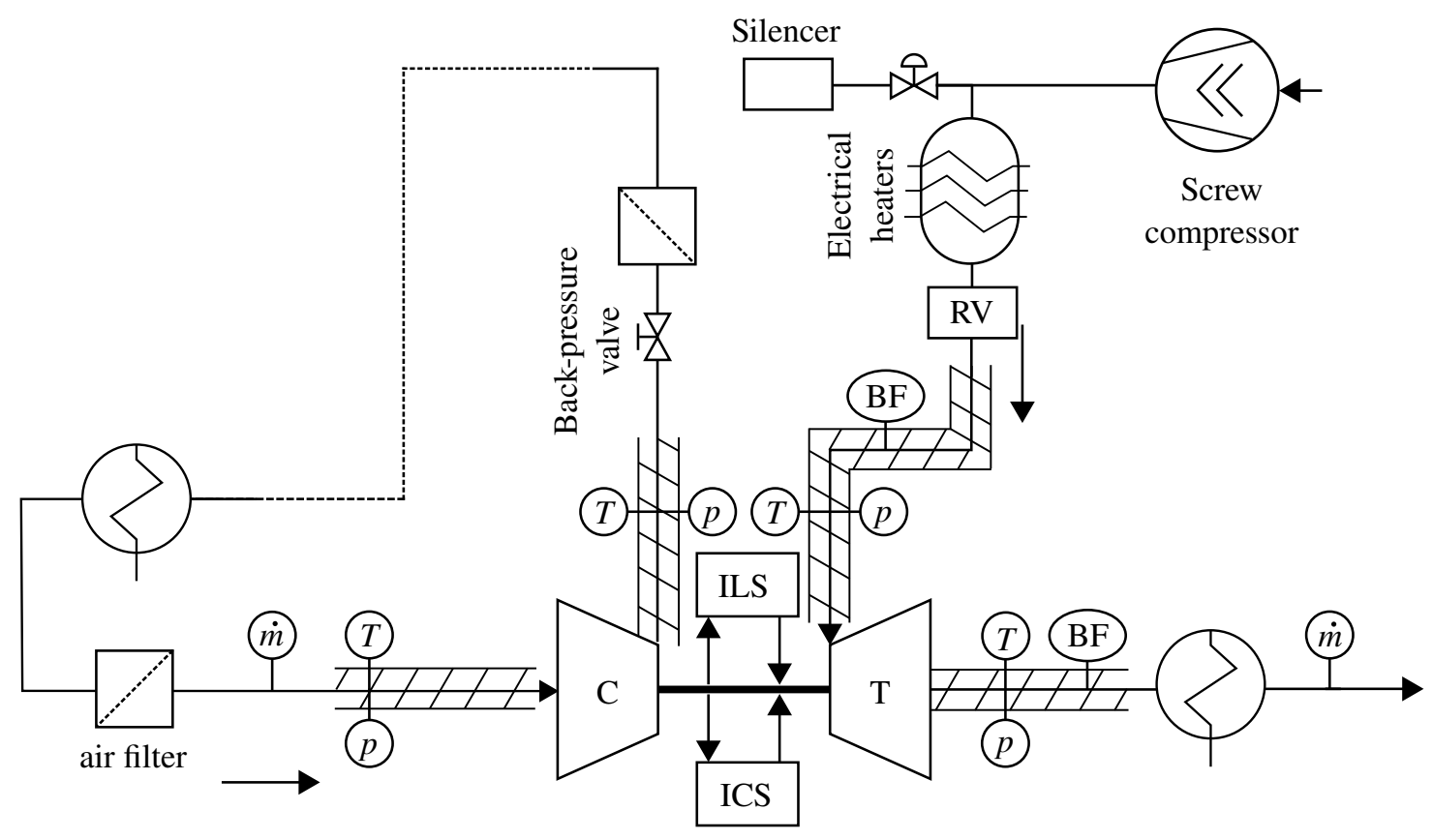

Figure 1. Gas stand schematic

Table 1. Gas stand measurement equipment

\begin{tabular}{cccc}
\hline Variable & Sensor type & Range & Typical expanded uncertainty \\
\hline Gas mass flow & Thermal flowmeter & $45 \mathrm{~kg} \mathrm{~h}^{-1}$ to $1230 \mathrm{~kg} \mathrm{~h}^{-1}$ & $<1 \%$ of reading output \\
Turbocharger speed & Inductive sensors & $0 \mathrm{krpm}^{-10} 300 \mathrm{krpm}$ & $<500 \mathrm{rpm}$ \\
Gas temperature & Type K thermocouple & $273 \mathrm{~K}$ to $1500 \mathrm{~K}$ & $1.5 \mathrm{~K}$ \\
Average gas pressure & Piezoresistive transmitter & $0 \mathrm{MPa}$ to $0.5 \mathrm{MPa}$ absolute & $12.5 \mathrm{hPa}$ \\
Turbine vanes position & Inductive displacement sensor & $0 \%$ to $100 \%$ & $<1 \%$ \\
Oil temperature & Platinum RTD & $173 \mathrm{~K}$ to $723 \mathrm{~K}$ & $<0.5 \mathrm{~K}$ \\
Oil pressure & Piezoresistive transmitter & $0 \mathrm{MPa}$ to $0.5 \mathrm{MPa}$ & $12.5 \mathrm{hPa}$ \\
Oil mass flow & Coriolis flow meter & $0 \mathrm{~g} \mathrm{~s}^{-1}$ to $50 \mathrm{~g} \mathrm{~s}^{-1}$ & $2 \%$ of reading output \\
\hline
\end{tabular}

insulated and the temperature of the compressor outlet air, turbine inlet air and lubrication were kept as similar as possible. The maximum allowed discrepancy between them was $\pm 6 \mathrm{~K}$, with an average value of $\pm 2.5 \mathrm{~K}$. There was no coolant flow during testing.

The turbine was characterised first in steady-state and quasi-adiabatic conditions, obtaining its characteristic maps. Then, it was measured activating the rotating valve at its inlet, imposing pulsating flow. The fundamental frequency of the pulses generated were $50 \mathrm{~Hz}, 66 \mathrm{~Hz}$ and $100 \mathrm{~Hz}$, corresponding to $1500 \mathrm{rpm}, 2000 \mathrm{rpm}$ and $3000 \mathrm{rpm}$ in a four cylinders four stroke engine. Different turbocharger speeds and turbine stator vanes positions were evaluated, corresponding to different points in an equivalent engine. The experimental points are shown in Table 2.

From now on, the pressure wave travelling from the rotary valve downstream towards the turbine inlet will be called incident pressure, whereas the wave travelling away from the turbine will be called reflected pressure. At the turbine outlet, the pressure wave travelling downstream will be called transmitted pressure. As the turbine outlet was not connected to an anechoic end, a second reflection pressure wave was also present, travelling towards the turbine at its outlet.

\subsection{One-dimensional simulation}

The simulation results that are presented in this study were obtained using OpenWAM [37], the 1D simulation integrated tool developed in CMT-Motores Térmicos, modified from its finite-differences formulation [38] to a finite-volume formulation. The method is described in detail in [26] and summarized in the appendix.

The turbine is modelled as a combination of onedimensional and zero-dimensional elements as seen in Figure 2. Section 0 is the domain inlet, upstream of the turbine. Section 1 is the turbine inlet. Section 2 is the volute lateral window. Section 2' is the stator nozzles throat section. Section 3 is the rotor inlet. Section 4 is the rotor outlet. Section 5 is the turbine outlet. Finally, section 6 is the domain outlet.

The turbine mass flow capacity and its power output are taken into account by means of two variable-size nozzles, one for the stator and one for the rotor, and an energy sink in the volume between them. The amount of energy taken each iteration is equal to the turbine power output times the time step, which is computed from the turbine efficiency at these conditions. Meanwhile, the area of the stator and the rotor nozzles are computed from the reduced mass flow as described by Serrano et al. [39]. The turbine reduced mass flow and adiabatic efficiency as a function 


\begin{tabular}{cccc}
\hline Case label & Equivalent engine speed [rpm] & Approx. vanes position [\%] & Fraction of maximum engine torque [\%] \\
\hline$\# 1$ & 2000 & 49 & $25 \%$ \\
$\# 2$ & 2000 & 47 & $100 \%$ \\
$\# 3$ & 3000 & 80 & $50 \%$ \\
$\# 4$ & 3000 & 58 & $75 \%$ \\
$\# 5$ & 3000 & 50 & $100 \%$ \\
$\# 6$ & 3500 & 55 & $100 \%$ \\
\hline
\end{tabular}

Table 2. List of pulsating-flow experimental points

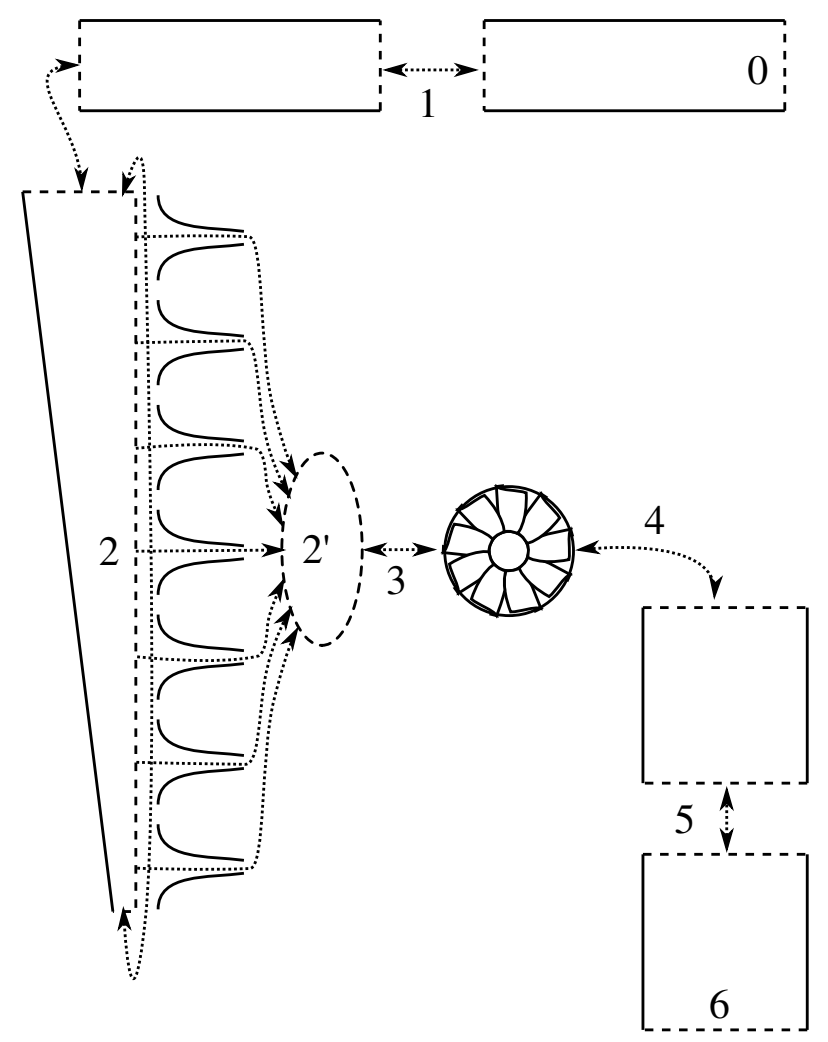

Figure 2. Turbine model schematic. The main sections are numbered.

of its expansion ratio, reduced speed and vanes position can be obtained by means of the turbine map provided by the manufacturer. Although in some simple cases these maps can be used directly as interpolation lookup tables, normally an extrapolation model is needed. In this work, the model described by Serrano et al. [27] is used to extrapolate the map. The extrapolation performance of this model was validated against extreme off-design conditions [40]. The reduced mass flow $\dot{m}_{\text {red }}$ is computed as in Equation 1 .

$$
\begin{aligned}
& \dot{m}_{\text {red }}= A_{\text {eff }} \sqrt{\frac{\gamma}{R_{\text {gas }}}}\left(\frac{1}{\pi_{\text {turb }}}\right)^{\frac{1}{\gamma}} \\
& \cdot \sqrt{\frac{2}{\gamma-1}\left[1-\left(\frac{1}{\pi_{\text {turb }}}\right)^{\frac{\gamma-1}{\gamma}}\right]}
\end{aligned}
$$

where $A_{\text {eff }}$ is the effective section of a nozzle that has the same reduced mass flow as the turbine with the same expansion ratio and working fluid, and $\pi_{\text {turb }}$ is the turbine total to static expansion ratio. The effective section is computed as in Equation 2.

$$
A_{\mathrm{eff}}=\frac{a \cdot A_{4} \cdot \sqrt{1+\frac{\sigma^{2} \cdot\left[\left(\frac{D_{4}}{D_{3}}\right)^{2}-1\right]+b}{\bar{\eta}}}}{\sqrt{1+\left(c \cdot \frac{A_{4}}{A_{2^{\prime}}}\right)^{2} \cdot \frac{\left(\frac{1}{\pi_{2^{\prime}, 4}}\right)^{2}}{\left\{1-\eta \cdot\left[1-\left(\frac{1}{\pi_{2^{\prime}, 4}}\right)^{\frac{\gamma-1}{\gamma}}\right]\right\}^{2}}}}
$$

where $a, b$ and $c$ are the fitting coefficients described by Serrano et al. [27]. $\eta$ is the total-to-static turbine efficiency, $\bar{\eta}$ is the average turbine efficiency, $D_{3}$ is the rotor inlet diameter, $D_{4}$ is the rotor outlet diameter, $A_{2^{\prime}}$ is the area at the stator nozzles outlet, $A_{4}$ is the rotor outlet area and $\pi_{2^{\prime}, 4}$ is the expansion ratio of the rotor, computed as in Equation 3 .

$$
\pi_{2^{\prime}, 4}=1+d \cdot\left(1-\pi_{\mathrm{turb}}\right)
$$

where, again, $d$ is a fitting coefficient. The turbine efficiency $\eta$ can be computed as in Equation 4

$$
\begin{aligned}
\eta= & -2 \cdot\left(\overline{\frac{D_{4}}{D_{3}}}\right)^{2} \cdot \sigma^{2} \\
& +\left(2 \cdot \frac{A_{\mathrm{eff}}}{A_{1}} \cdot z \cdot \tan \alpha_{3}+\frac{\overline{D_{4}}}{D_{3}} \cdot \tan \beta_{4}\right) \cdot \pi_{\text {turb }}^{-\frac{1}{\gamma}} \cdot \sigma
\end{aligned}
$$

where $\overline{D_{4}}$ is the average rotor outlet diameter, $\sigma$ is the blade speed ratio, $\alpha_{3}$ is the flow angle at the rotor inlet, $\beta_{4}$ is the flow angle at the rotor outlet, and $\gamma$ is the specific heat capacities ratio. $z$ is a correction term that can be computed with the expression shown in Equation 5.

$$
z=\left(e \cdot N_{\text {red }}+f\right) \cdot \sigma+\left(g \cdot N_{\text {red }}+h \cdot r^{2}+i \cdot r+j\right)
$$

where $e, f, g, h, i$, and $j$ are fitting parameters, $N_{\text {red }}$ is the turbine reduced speed, and $r$ is the turbine stator vanes position.

Each time step, Equation 2 and Equation 4 are solved iteratively until convergence. Then, the effective area is used to compute the effective section of the stator nozzles and the rotor and set as the area of the boundary conditions of the one-dimensional and zero-dimensional elements in contact with sections 2 and 4 . The efficiency is used as described previously.

The simulations are carried out imposing incident pressure pulses as boundary conditions at different vanes positions, average expansion ratios and reduced speeds. 


\subsection{Acoustic transfer matrix generation}

Two transient simulations are performed for each turbine map point where the acoustic transfer matrix is generated. In these simulations, the turbine inlet and outlet are connected to incident pressure boundary conditions, where the pressure waves travelling towards the turbine are imposed. Also, the rotational speed of the rotor is kept constant and equal to the one corresponding at that turbine map point. During the first simulation, the pressure wave at the turbine outlet has a constant value whereas the pressure wave at the turbine inlet introduces low amplitude white noise with an average pressure value corresponding to the turbine map point. In the second simulation, the turbine inlet pressure wave is kept constant while low amplitude white noise is imposed at the turbine outlet.

During the first simulation, the turbine outlet acts as an anechoic end, so the pressure waves travelling upstream at the turbine inlet and downstream at the turbine outlet are produced only due to the turbine inlet imposed pressure wave. During the second simulation, the roles are inverted and the backward-travelling pressure pulse at the turbine inlet and the forward-travelling pressure pulse at the turbine outlet are a consequence of the imposed pulse at the turbine outlet boundary condition. The results of the simulation are processed, discarding the first $0.25 \mathrm{~s}$ to ensure convergence, approximating the power spectral density of the pressure waves by means of Welch's method [41] with a Hanning window. Then, an expression in the form of Equation 6 can be computed.

$$
\left(\begin{array}{cc}
R_{\text {in }} & T_{\text {out,in }} \\
T_{\text {in,out }} & R_{\text {out }}
\end{array}\right) \cdot\left(\begin{array}{c}
P_{\text {in }}^{+} \\
P_{\text {out }}^{-}
\end{array}\right)=\left(\begin{array}{c}
P_{\text {in }}^{-} \\
P_{\text {out }}^{+}
\end{array}\right)
$$

In the left term of Equation 6, the matrix corresponds to the acoustic transfer matrix (ATM). In the same equation, the subscript in represents the turbine inlet and the subscript out the turbine outlet. The pressures $P$ are computed in the frequency domain. The superscript ${ }^{+}$refers to a pressure wave travelling downstream, whereas ${ }^{-}$refers to a pressure wave that travels upstream. The reflection coefficients $R_{\text {in }}$ and $R_{\text {out }}$ can be computed as in Equation 7 .

$$
R_{\text {in }}=\left.\frac{P_{\text {in }}^{-}}{P_{\text {in }}^{+}}\right|_{\text {first sim. }}, \quad R_{\text {out }}=\left.\frac{P_{\text {out }}^{+}}{P_{\text {out }}^{-}}\right|_{\text {second sim. }}
$$

The transmission coefficients $T_{\text {out,in }}$ and $T_{\text {in,out }}$ are computed as in Equation 8

$$
T_{\text {out,in }}=\left.\frac{P_{\text {in }}^{-}}{P_{\text {out }}^{-}}\right|_{\text {second sim. }}, \quad T_{\text {in,out }}=\left.\frac{P_{\text {out }}^{+}}{P_{\text {in }}^{+}}\right|_{\text {first sim. }}
$$

This procedure is shown schematically in Figure 3 . Once the acoustic transfer matrices are assembled, they supplant the whole turbine model represented in Figure 2 in terms of fluid acoustics computation.

\subsection{Acoustic transfer matrix interpolation from lookup table}

After generating the lookup table, a standard interpolation method can be used to obtain the acoustic transfer matrix function needed for any turbine operating point. For a

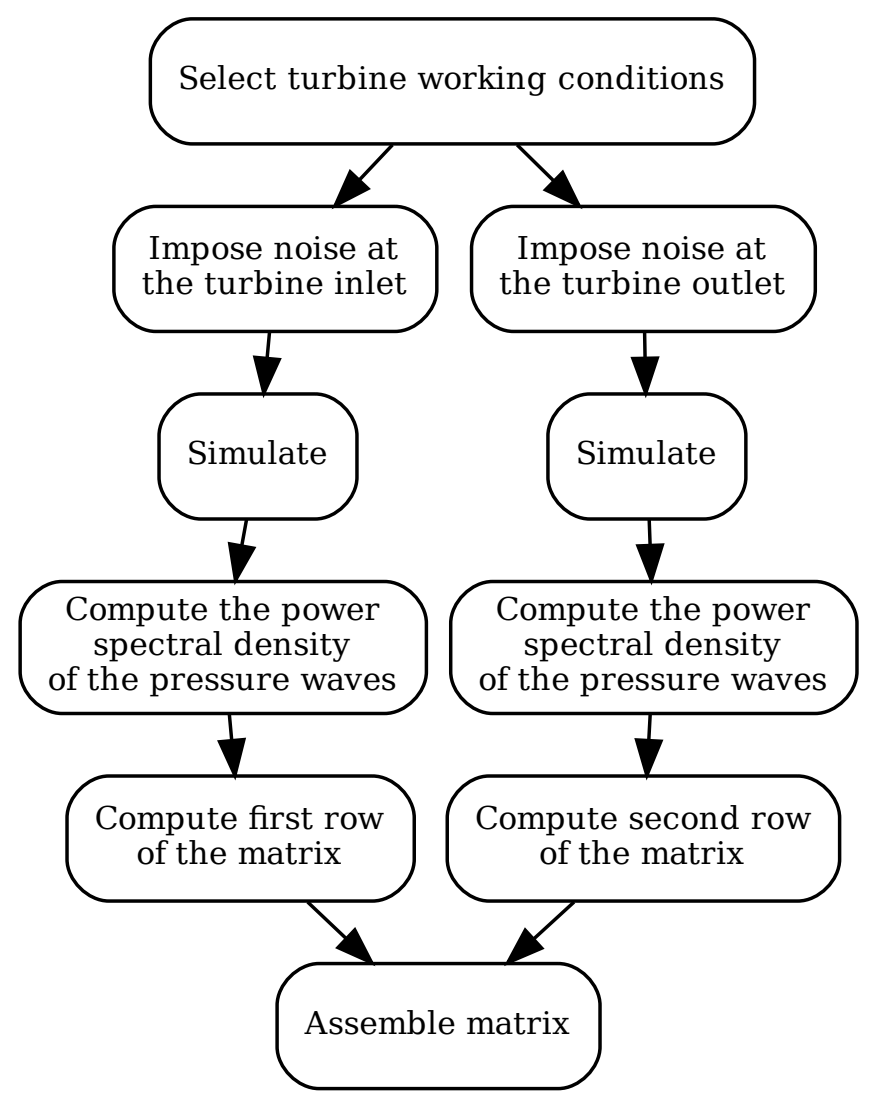

Figure 3. Flowchart of the acoustric transfer matrix generation

point of reduced speed $N_{\text {red }}$, expansion ratio $\pi_{\text {turb }}$ and vanes position $r$, six values of the acoustic transfer matrix lookup table are searched for: the immediately lower and higher reduced speeds, $N_{\text {red }}^{\text {lower }}$ and $N_{\text {red }}^{\text {upper }}$; the immediately lower and higher expansion ratios, $\pi_{\text {turb }}^{\text {lower }}$ and $\pi_{\text {turb }}^{\text {upper }}$; the inmediately lower and higher vanes positions, $r^{\text {lower }}$ and $r^{\text {upper }}$. Then, a simple trilinear interpolation can be performed, using the values of $T_{\text {in,out }}, T_{\text {out,in }}, R_{\text {in }}$ and $R_{\text {out }}$ stored in the lookup table for the eight combinations of lower and higher values of reduced speed, expansion ratio and vanes position.

The mass flow and efficiency of the turbine can be computed directly from Equation 1 and Equation 4, and the flow speed and temperature can be easily obtained and used to get the behaviour of the elements downstream of the turbine.

\section{Results}

The objective of this section is to evaluate the performance of the IATM method in terms of turbine acoustic prediction when compared to conventional one-dimensional simulations as well as to demonstrate its potential and simple implementation. With this purpose, an experimental validation with the data obtained by Galindo et al.[26] is first presented. Secondly, a sensitivity study in terms of interpolation mesh resolution is performed to explore the strengths and limitation of the method. Finally, a complete analysis of the turbine acoustics with the main operation variables of the turbine is exposed. 


\subsection{Experimental validation}

The 1D model used as a base for the interpolation method developed in this paper has been fully validated by Galindo et al. [26]. The experimental turbine map shown in Figure 4 is fed to the model and, during the preprocessing step, a complete extrapolated map based on equivalent effective areas and efficiencies [27] is generated.

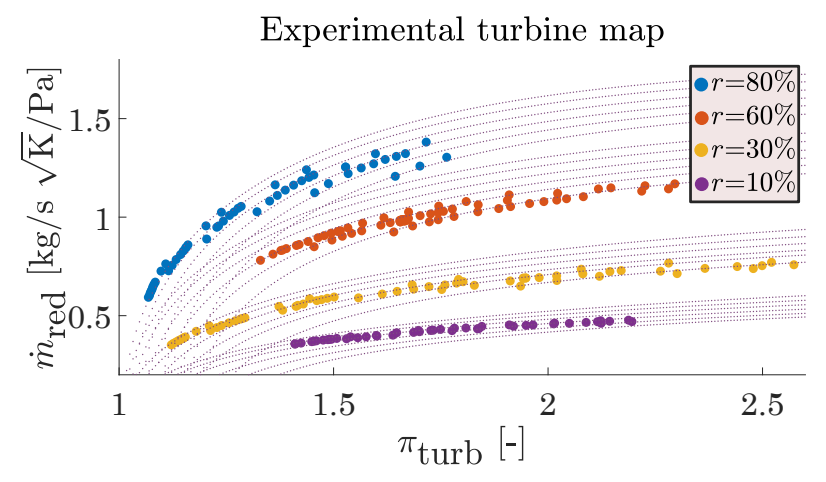

Figure 4. Turbine map obtained from steady state measurements

The next results include the simulations obtained using the IATM method, with the aim of performing a comparison with the fully $1 \mathrm{D}$ results. The IATM results are obtained after the interpolation of the acoustic matrices calculated from the 1D model following the method described in the section called Method description. Thus, when comparing with the experiments, any improvement of the IATM in the accuracy should be interpreted as a matter of chance. As explained in detail by Galindo et al. [26], for carrying out the validation, the incident and second reflection components are imposed in the inlet and outlet of the turbine respectively. The reflected and transmitted waves are predicted and compared with the experiments to evaluate the capability of the model to recreate the turbine acoustics. Considering that the simulation cost of the IATM method would be significantly lower when only a preprocessing is needed, the usefulness of the tool will be evident as long as the results are reasonably similar to the ones provided by the 1D model.

In Figure 5 and Figure 6 the results obtained with the 1D model and with the IATM are presented, along with the experimental results. A summary of the conditions of the main experimental points is presented in Table 2, covering different operation conditions in terms of engine speed, engine load, and variable geometry turbine (VGT) position. The plots are divided into two subplots. In the first subplot, the power spectral density (PSD) is showed from $0 \mathrm{~Hz}$ to $650 \mathrm{~Hz}$. On the other hand, the subplot on the bottom indicates the error against experiments of the harmonics, calculated for both the 1D and the IATM method.

Observing the results from Figure 5 and Figure 6 it can be stated that the IATM method effectively reproduced the 1D performance. Not in vain, both the PSD graph and the error are almost identical using both models, for all the cases, in both reflected and transmitted waves. The biggest difference between IATM and 1D is seen probably in the reflection of case 6 at $600 \mathrm{~Hz}$. When comparing with experiments, the error is maintained lower than $6 \mathrm{~dB}$ for frequencies below $500 \mathrm{~Hz}$ in almost all the cases, with the exception of case 2transmitted (Figure 5d), case 3-reflected (Figure 5e) and case 6-transmitted (Figure 6f), where an error of around $12 \mathrm{~dB}$ appears near $500 \mathrm{~Hz}$.

As it has been previously stated, the aim of this validation is not to evaluate the discrepancies with the experiments but to prove that the IATM method provides similar results as the considerably more expensive 1D model. In this sense, in the light of the results presented, the IATM method arises as a reliable and computationally efficient alternative to the 1D method for turbine acoustics prediction in low and medium frequencies. 

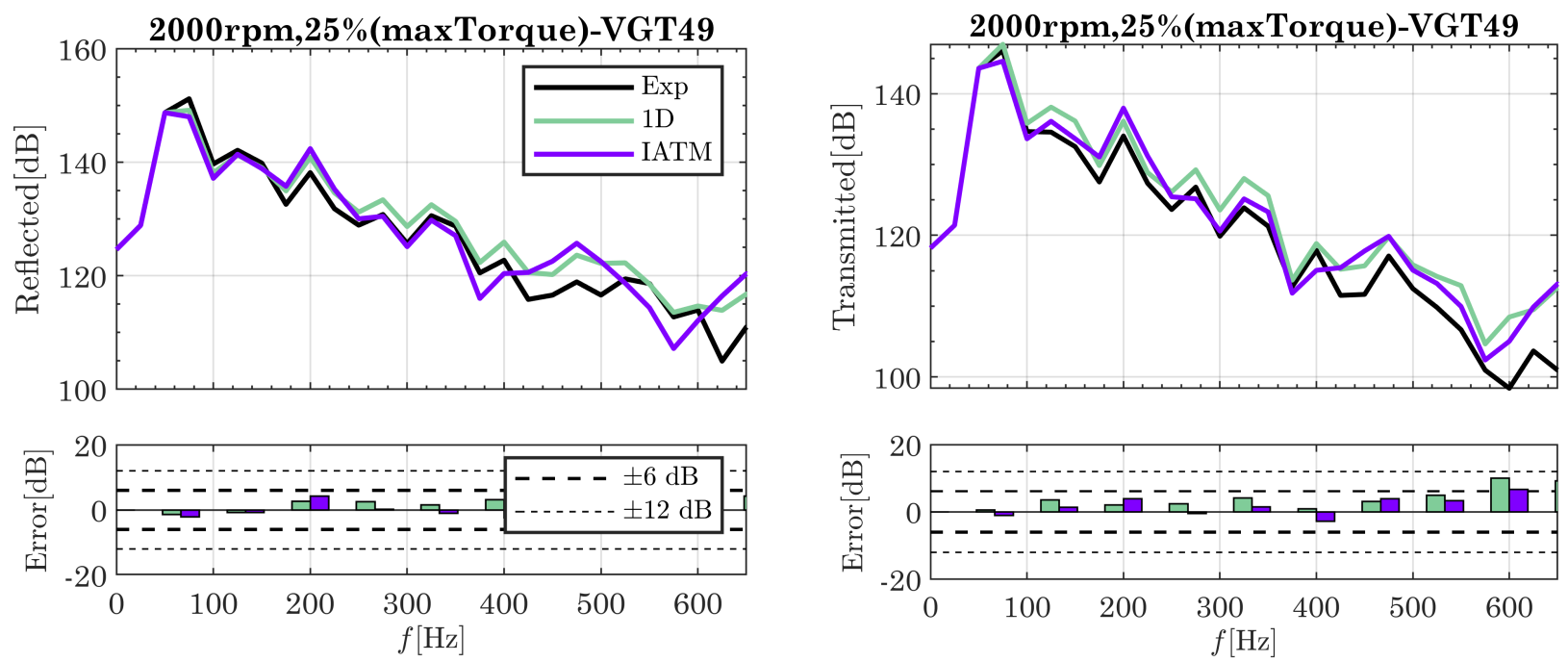

(a) Reflected wave results

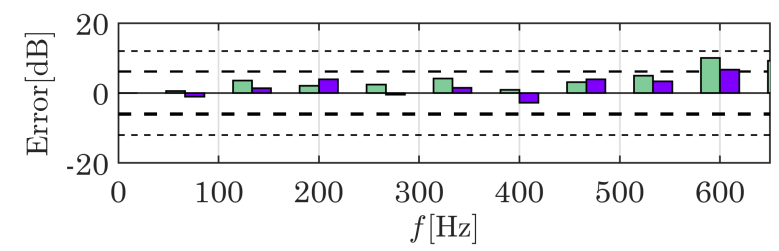

(b) Transmitted wave results
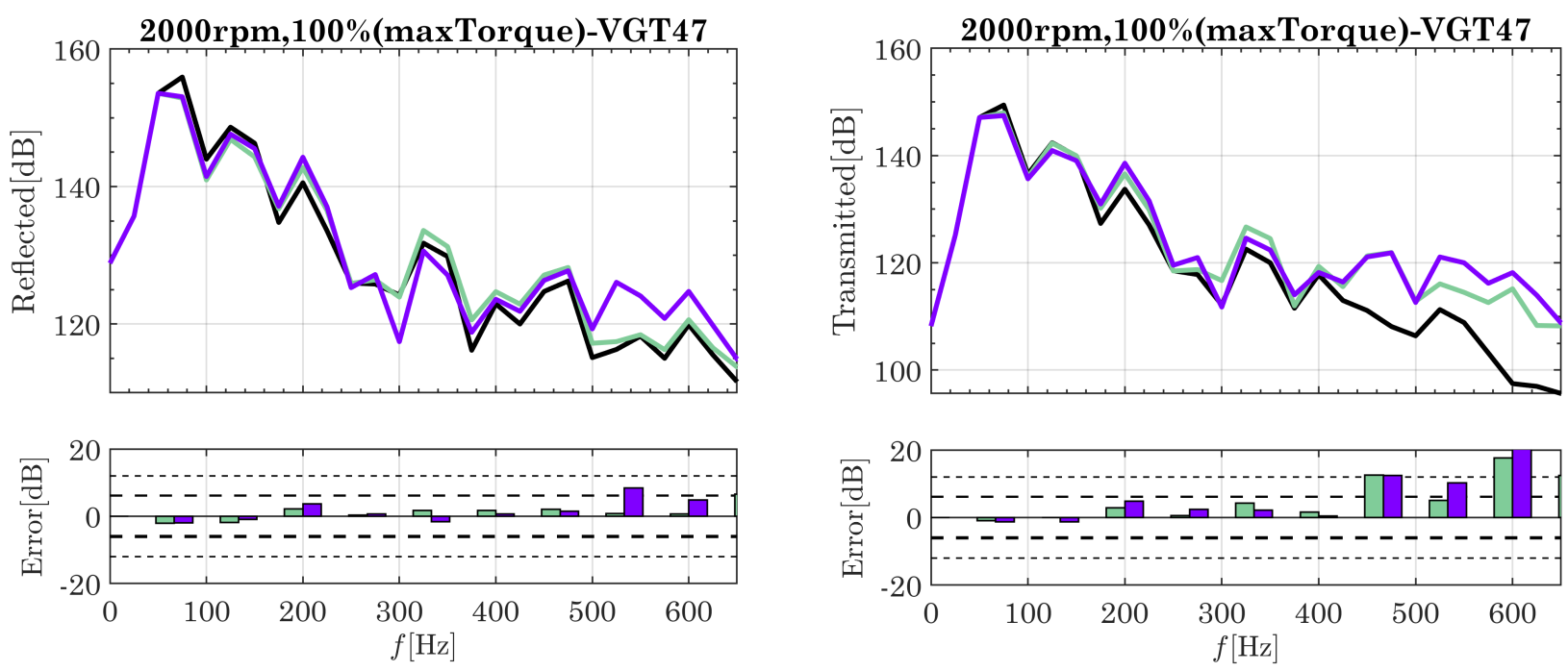

(c) Reflected wave results

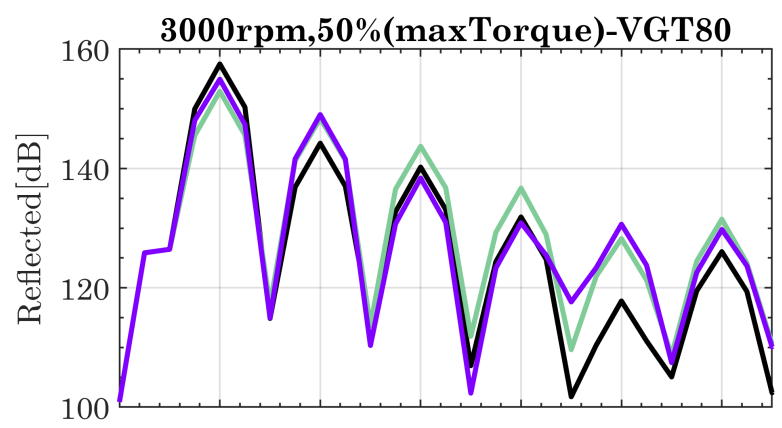

(d) Transmitted wave results
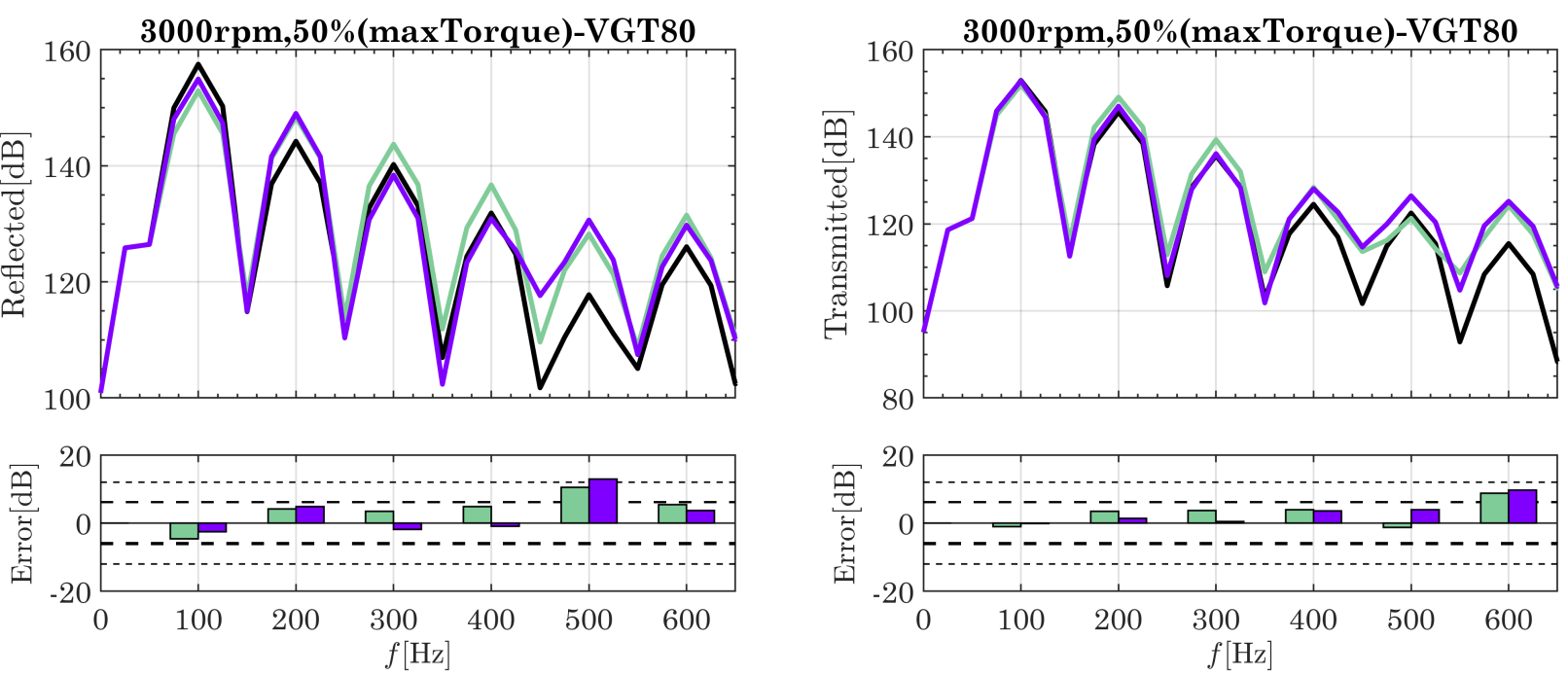

(e) Reflected wave results

(f) Transmitted wave results

Figure 5. PSD results validation. Reflected and transmitted for case $1(a, b)$, case $2(c, d)$ and case $3(e, f)$ 

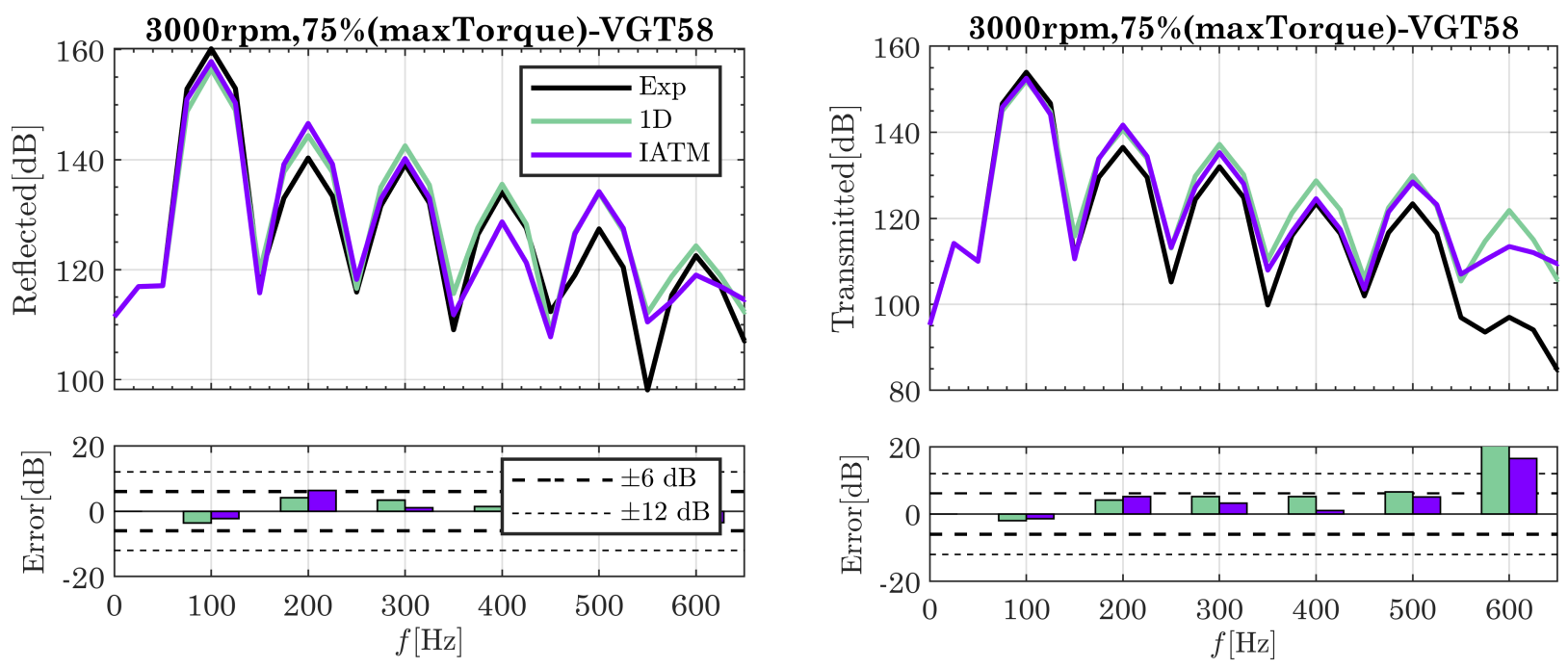

(a) Reflected wave results

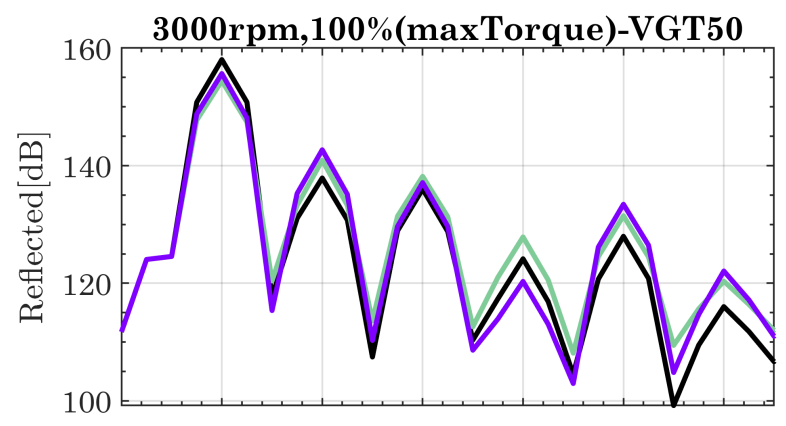

(b) Transmitted wave results
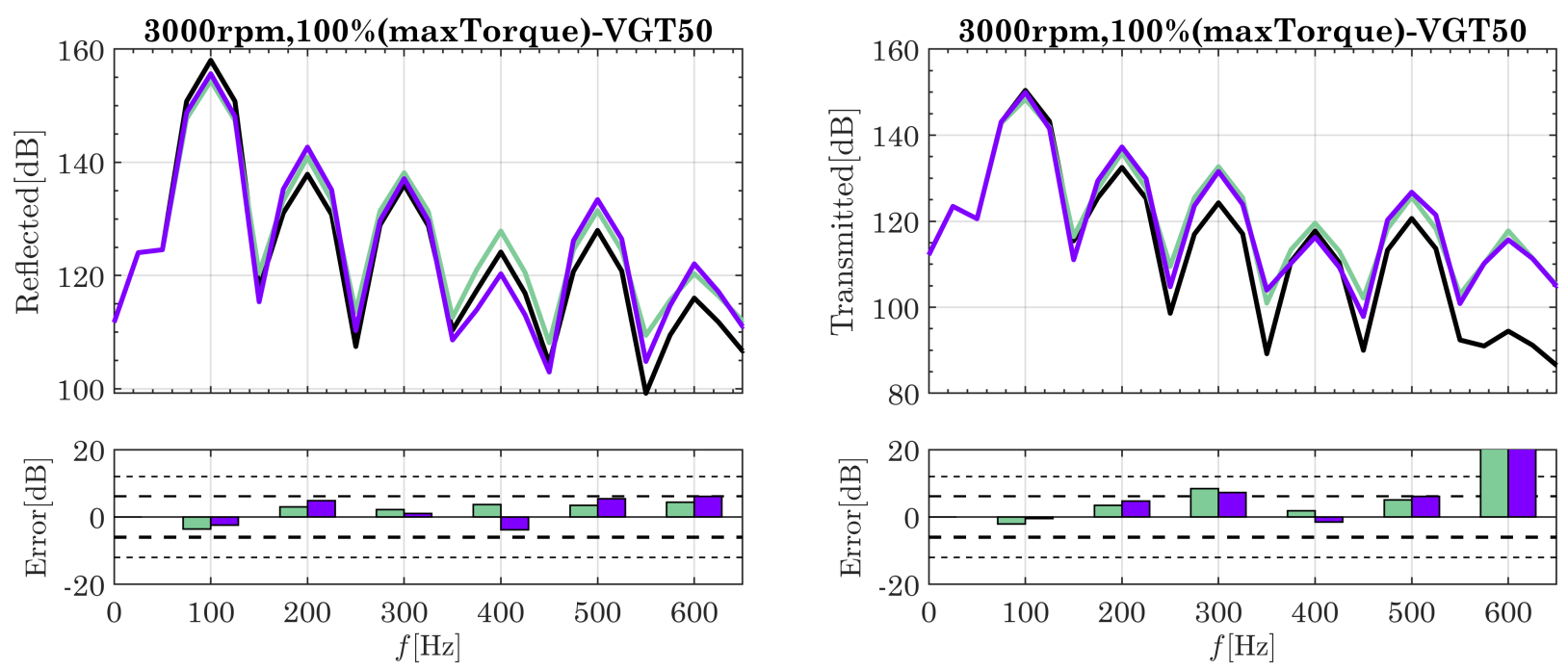

(c) Reflected wave results

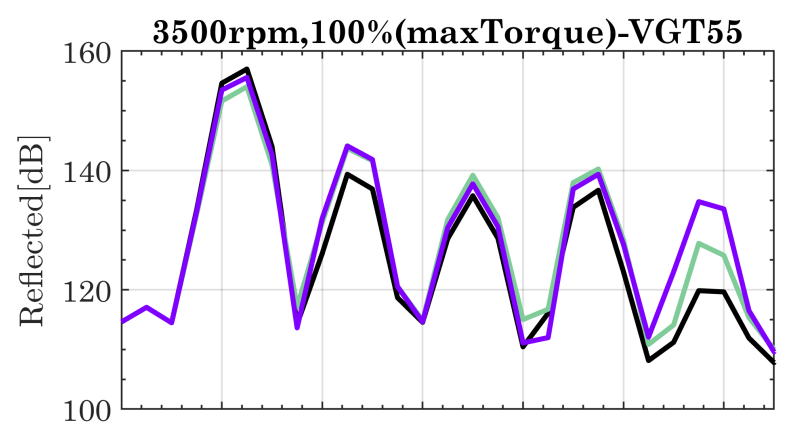

(d) Transmitted wave results
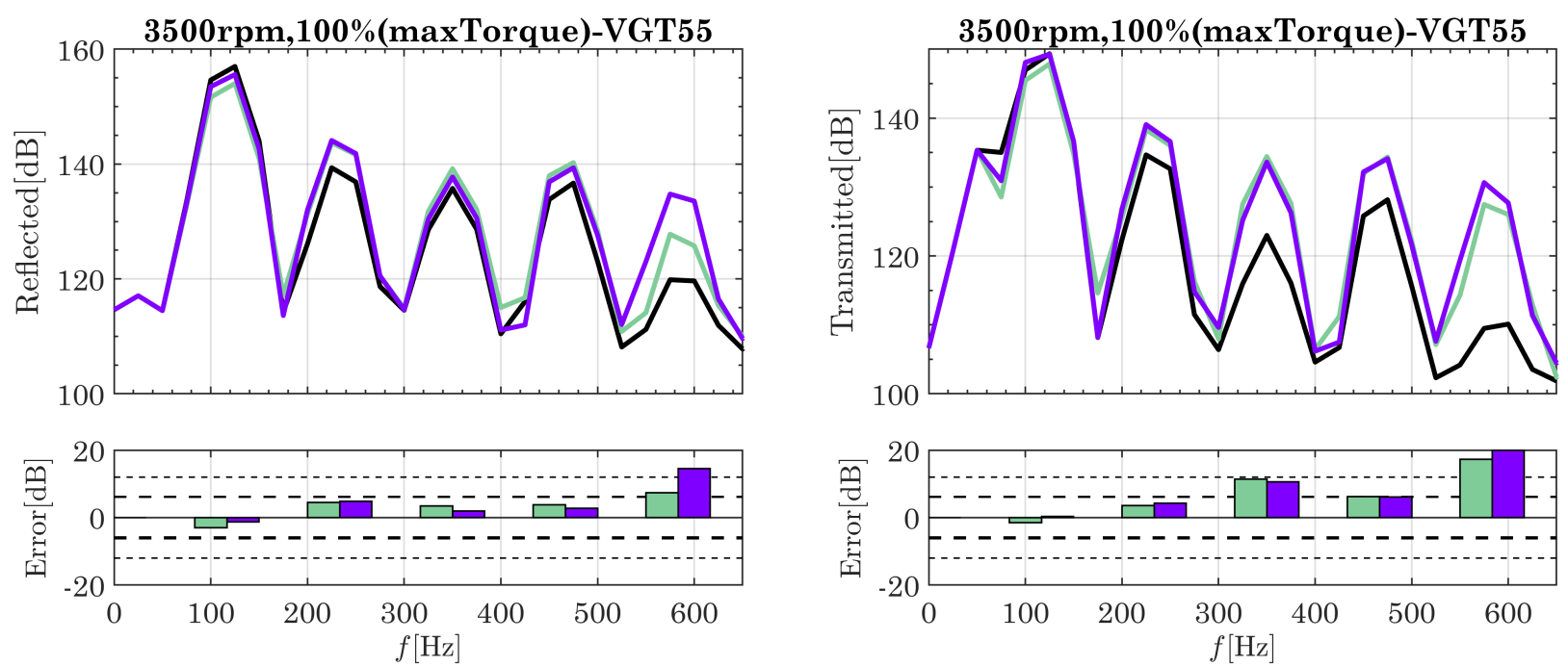

(e) Reflected wave results

(f) Transmitted wave results

Figure 6. PSD results validation. Reflected and transmitted for case $4(\mathrm{a}, \mathrm{b})$, case $5(\mathrm{c}, \mathrm{d})$ and case 6 (e,f) 


\subsection{Lookup table resolution sensitivity study}

The procedure that has been followed in order to build the acoustic transfer matrices have been previously exposed in the section titled Method description along with the description of the interpolation method from lookup tables. In the following paragraphs, a study of the resolution of the interpolation mesh, in addition to some indications of the criteria for selecting the mesh points, are presented. This information could be relevant, considering that different mesh resolutions will lead to different computational time during the computation of the interpolation matrices. Furthermore, the specific selection of the points chosen for building the mesh might be a good indicator of the robustness of the procedure, as the benefit of the method relies on the ability to predict operating points even when they are reasonably far from the ones that constitute the interpolation mesh.

In Table 3 there is a summary of the relevant information used to perform this study. The first row includes the data of the main turbine parameters for the six experimental points used in the previously discussed experimental validation. The second row, referenced as base mesh, includes the data of the main turbine parameters used for the mesh configuration selected for the experimental validation. Two additional rows are included, one for a thin mesh configuration and another for a coarse mesh. These two additional computational meshes have been tested for performing a mesh sensitivity analysis. For each additional mesh configuration, Table 3 indicates the turbine operation parameters used for computing the interpolation mesh. As the reader can notice, the parameters selected for building the mesh are different from the ones in the experiments in all three configurations, otherwise it would no be possible to test the reliability of the interpolation.

The IATM method has been applied using the additional two mesh configurations, coarse mesh and thin mesh, and then compared with experiments and the 1D model. For clarity's sake, only a summary of the mesh sensitivity study results will be shown, as the conclusion obtained is sufficiently evident to be presented in a single chart. In Figure 7, the root-mean-square error obtained for the reflected and transmitted component, is presented for all the mesh configurations in the six cases studied. The RMSE is computed using the error of the first six harmonics when comparing the experiment and the simulations of each of the IATM mesh configurations.

As it can be observed in Figure 7, results of RMSE are extremely similar for all the mesh configurations in both the reflected and the transmitted components. Furthermore, the error is in general less than $5 \mathrm{~dB}$, except for case 6 .

From these results it can be concluded that the interpolation method is robust, stable and accurate, as it provides very similar results to the $1 \mathrm{D}$ model, even with the coarse mesh where only 27 points are used for the mesh computation.

\subsection{Computational cost}

In order to obtain the acoustic transfer matrix of one single operating point, two simulations of $1.25 \mathrm{~s}$ are performed and
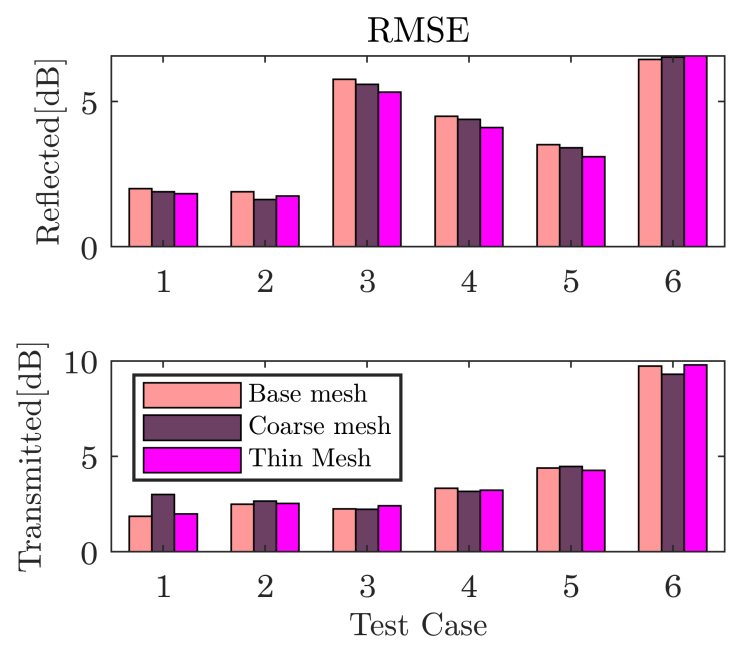

Figure 7. RMSE of the IATM with different mesh resolutions.

their results are processed. Running sequentially, the total time in an Intel ${ }^{\circledR X}$ eon ${ }^{\circledR E} 5-2640 \mathrm{v} 4 \mathrm{CPU}$ at $3 \mathrm{GHz}$ is $90 \mathrm{~s}$.

The computational cost for computing the matrices increases linearly with the density of the mesh as expected. In particular, the coarse mesh takes half of the time as the base mesh, and the thin mesh takes double time of the base mesh, as it has the double quantity of points. However, the interpolation matrices are computed during preprocessing and thus, the computational cost might not be determinant when configuring the method. The relevant fact is that using this method, the turbine acoustics are already obtained before the simulation and thus, only lookup table computations are required during further uses. Also, the procedure of filling the lookup table is extremely parallel, so it can be naturally run in multiple computational cores. In fact, once the calculation of the acoustic matrices is amortized in the preprocessing, faster than real time conditions can be easily reached. In contrast, the Intel machine above mentioned needs around 15 seconds to compute each second of the same simulation case when running the complete 1D model represented in Figure 2

A faster than real time turbine model with acoustic capabilities such as the one presented in this work can be easily coupled with other real time or faster than real time simulation elements, including some of the newest models for catalytic converters [42] or gas exchange models [43].

\subsection{Turbine acoustic performance analysis}

At this stage, it has been demonstrated that the IATM method provides very similar results as a $1 \mathrm{D}$ model in terms of accuracy, but implying a much lower computational cost. The results of the interpolation mesh is, furthermore, considerably robust even when using a low quantity of mesh points (coarse mesh). But it is not less important to prove the usefulness of the method with an example of a turbine acoustic performance analysis. The next results use the same turbine as the rest of the manuscript. From the steady state experimental test, the turbine map of Figure 4 is obtained. With this turbine map, the interpolation mesh is generated and then, a complete analysis of the turbine acoustics can be performed using the IATM method. 


\begin{tabular}{ccccc}
\hline Configuration & Mesh resolution & $N_{\text {red }}\left[\mathrm{Hz} \mathrm{K}^{-0.5}\right]$ & $r[\%]$ & $\pi_{\text {turb }}$ \\
\hline Exp & - & $50,95,85,104,106,107$ & $49,47,80,58,50,55$ & $1.35,2.341 .66,2.28,2.58,2.4$ \\
Base mesh & 108 & $43,86,129$ & $10,40,90$ & $1.35,2.341 .66,2.28,2.58,2.4$ \\
Coarse Mesh & 54 & $43,86,129$ & $10,40,90$ & $1.1,1.6,2.6$ \\
Thin mesh & 216 & $43,86,129$ & $10,30,60,90$ & $1.1,1.2,1.4,1.6,1.8,2,2.2,2.4,2.6$ \\
\hline
\end{tabular}

Table 3. Mesh sensitivity study

For the following analysis, the base mesh configuration is used. The effective area of the 54 turbine operating points of the interpolation mesh is shown in Figure 8. The effective area will have a crucial role in the acoustics performance as it will be shown in the following paragraphs.

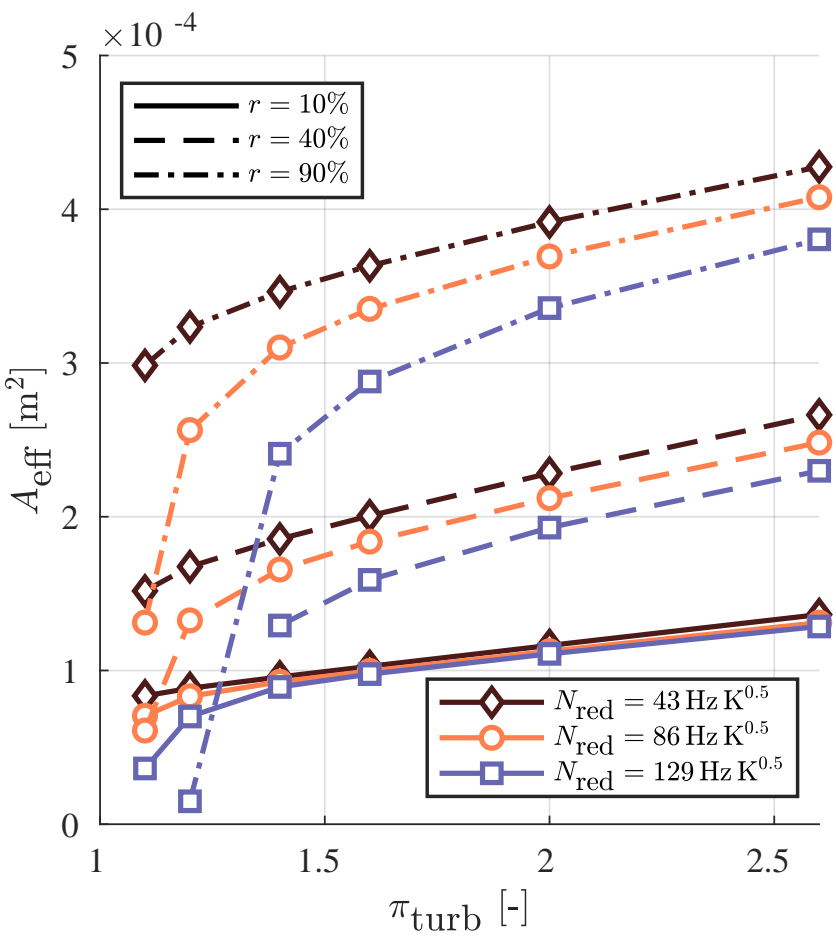

Figure 8. Equivalent turbine effective area of the operating points used for the generation of the interpolation mesh (being $r$ the vane position).

Once the preprocessing is finished and the acoustic matrices are obtained, there are several possibilities in terms of ways of studying the acoustic performance of the turbine. However, the study presented is focused in the behaviour of the transmission loss (TL) when confronted to the main parameters of the turbine operation, i.e., the expansion ratio, the vanes position and the turbocharger speed, as well as the equivalent effective area shown in Figure 8 . The transmission loss is defined as the ratio between the transmitted pressure wave and the incident pressure wave, $P_{\text {out }}^{+} / P_{\text {in }}^{+}$, and is expressed in $\mathrm{dB}$. Thus, it quantifies the attenuation that the incident wave faces when travelling through the turbine towards the outlet pipe (inlet of the aftertreatment system). The main objective of the following results is to illustrate the potential of the method when analysing the acoustic performance rather than to fully understand the specific behaviour of this turbine specimen.

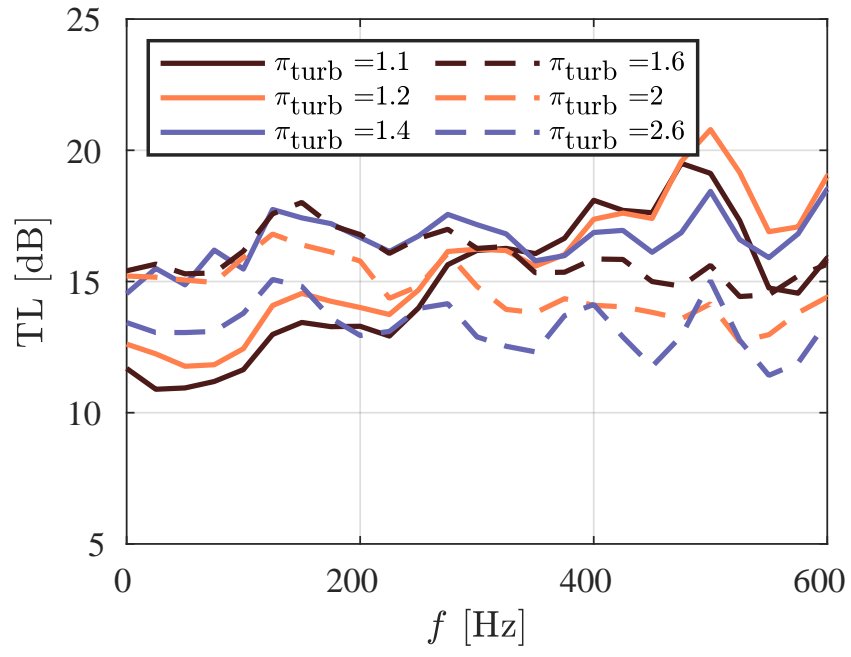

(a) Vanes position at $10 \%$, reduced speed equal to $129 \mathrm{~Hz} \mathrm{~K}^{-0.5}$

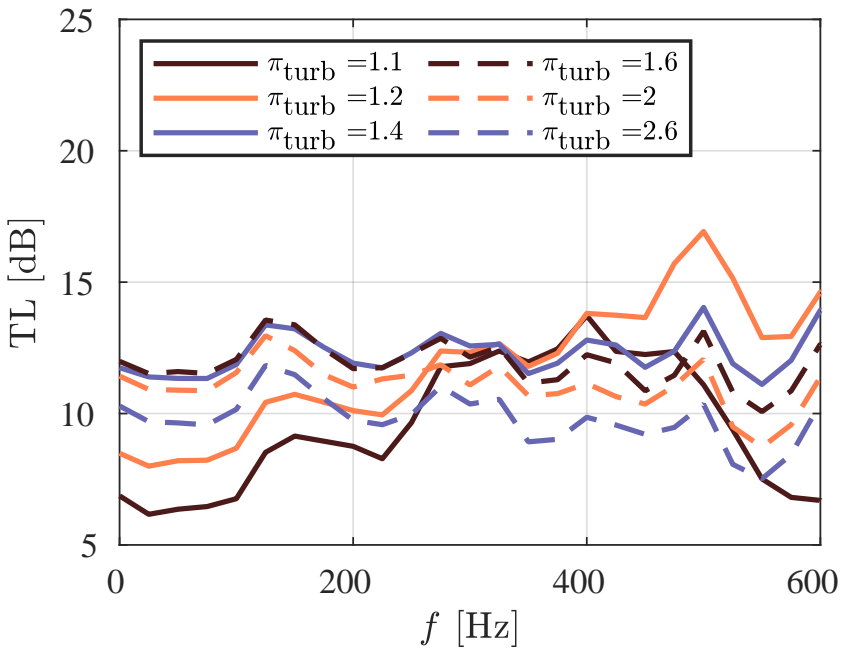

(b) Vanes position at $40 \%$, reduced speed equal to $86 \mathrm{~Hz} \mathrm{~K}^{-0.5}$

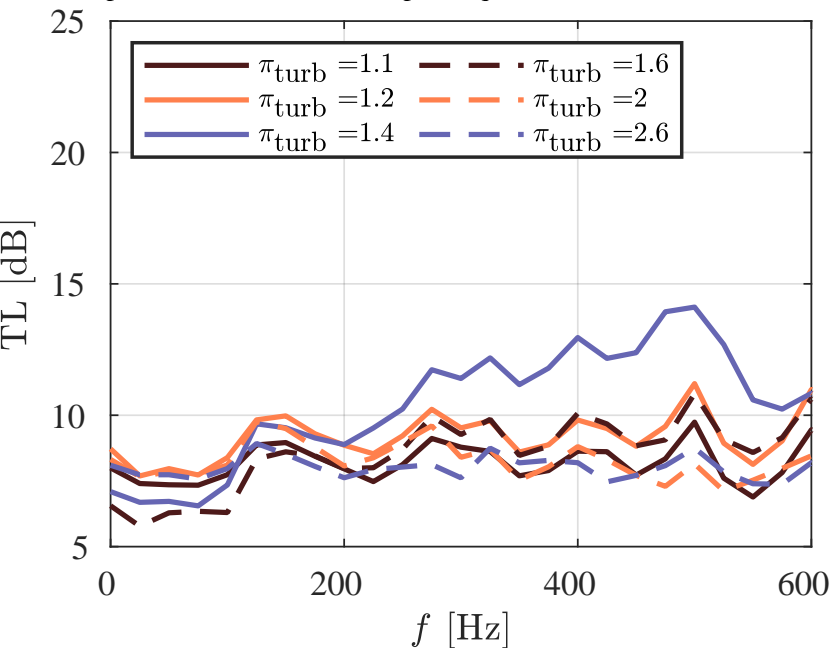

(c) Vanes position at $90 \%$, reduced speed equal to $129 \mathrm{~Hz} \mathrm{~K}^{-0.5}$

Figure 9. Transmission loss evolution in frequency 

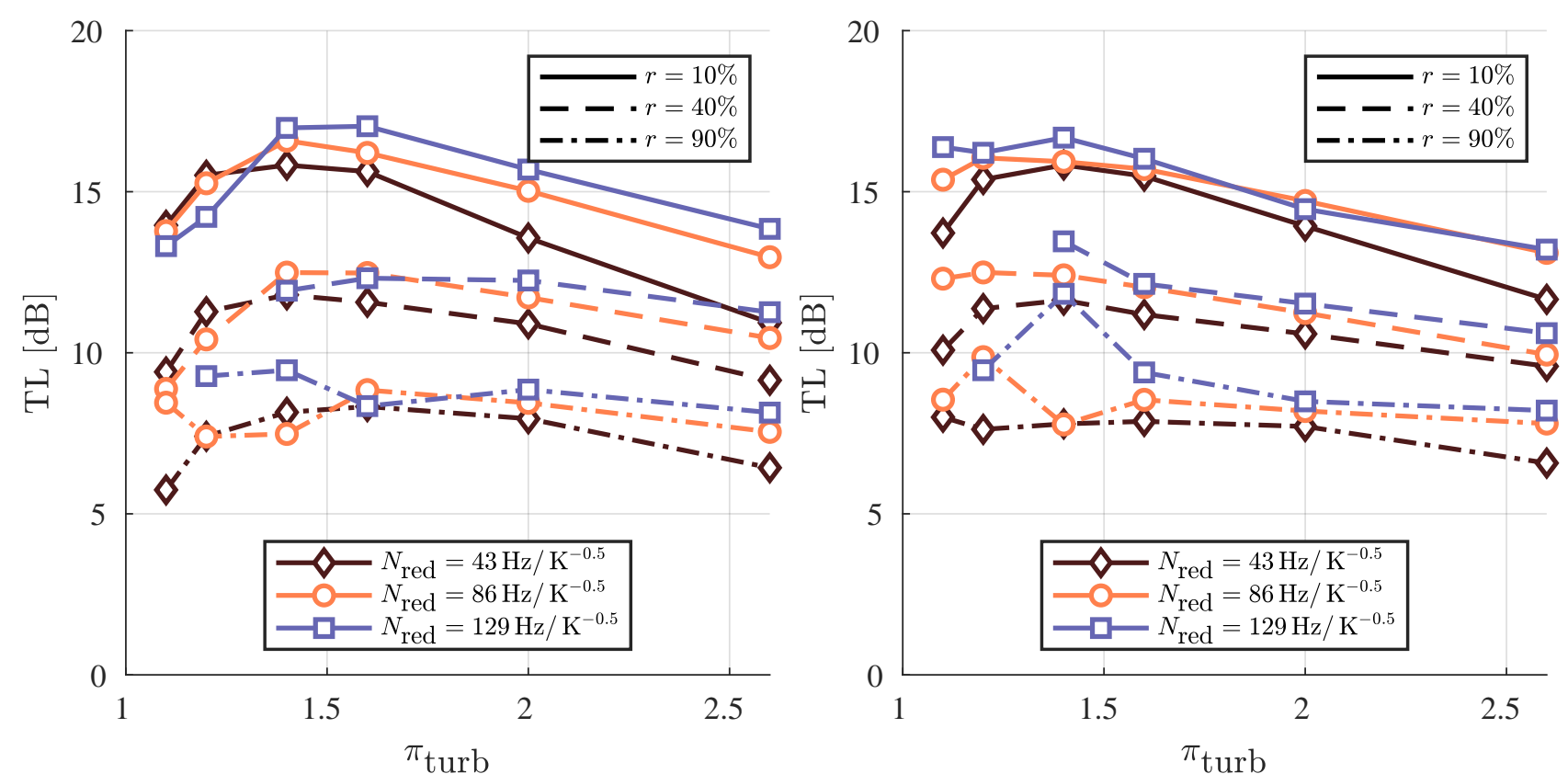

(a) $f=0 \mathrm{~Hz}$ to $150 \mathrm{~Hz}$

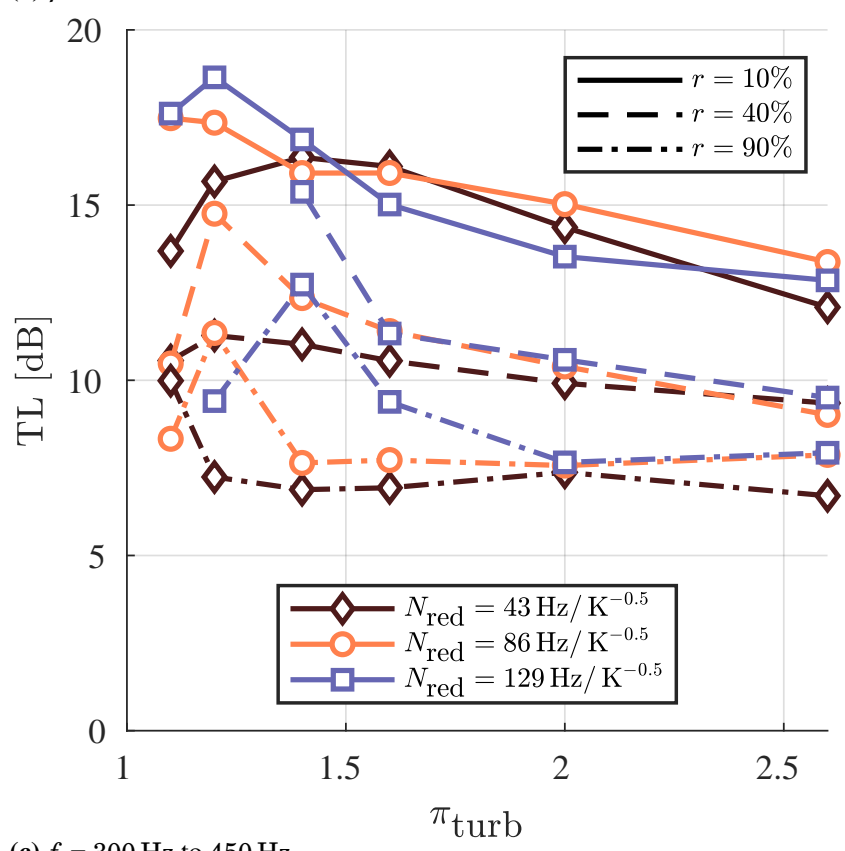

(b) $f=150 \mathrm{~Hz}$ to $300 \mathrm{~Hz}$

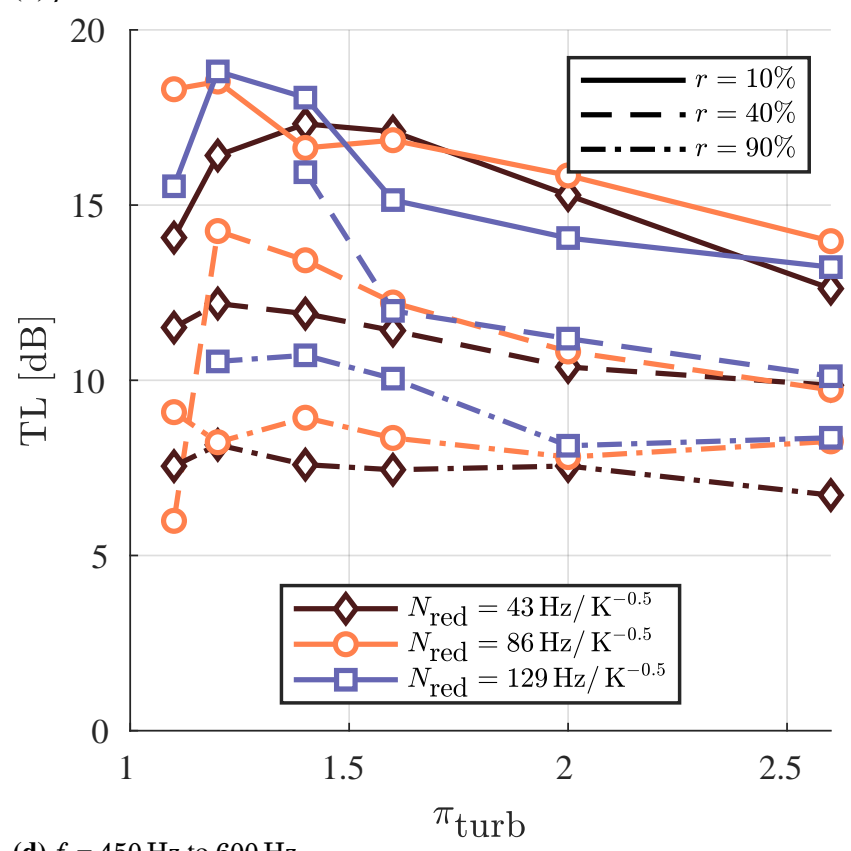

Figure 10. Transmission loss against the expansion ratio of the turbine, averaged at different frequency bands 

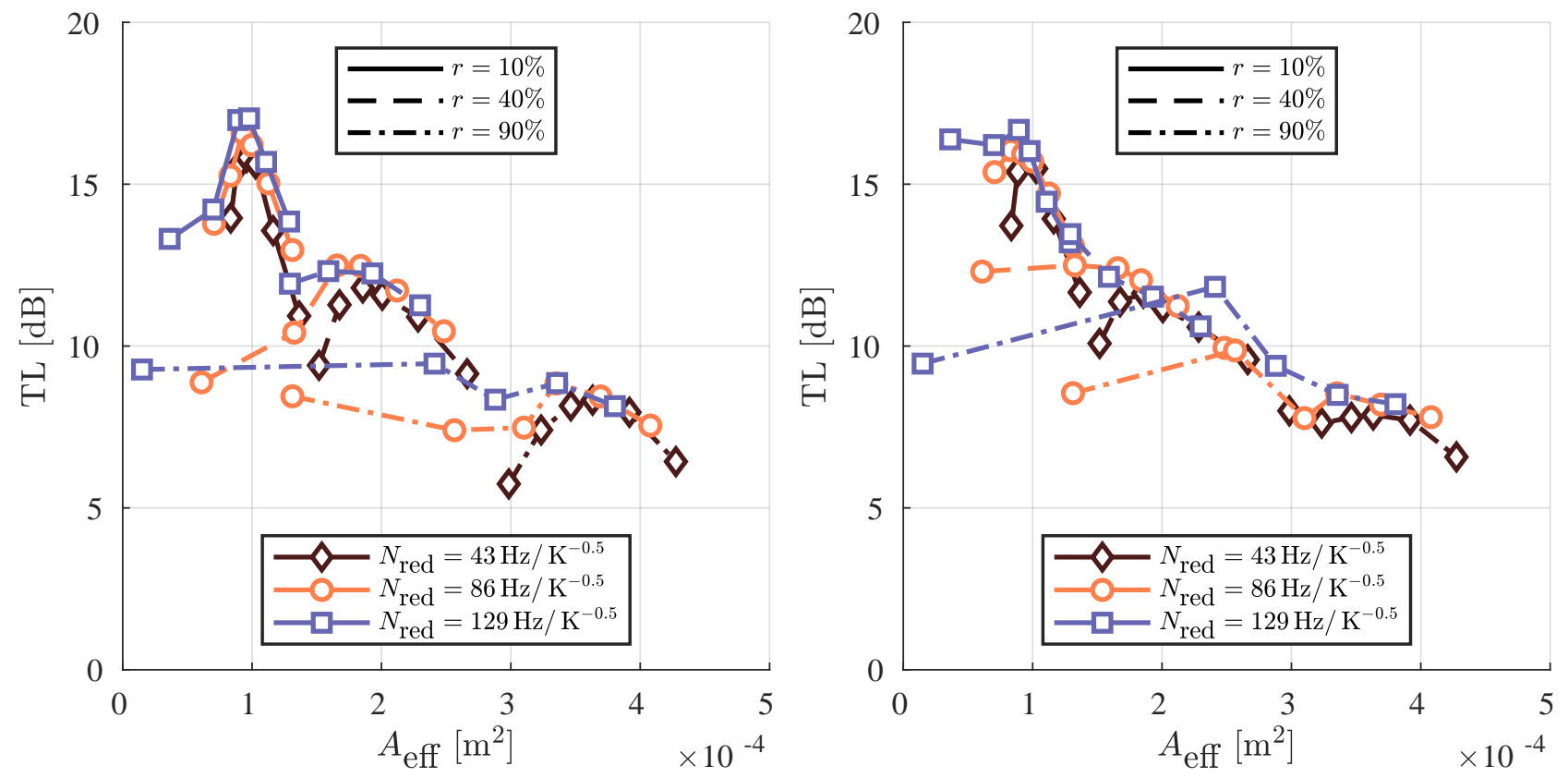

(a) $f=0 \mathrm{~Hz}$ to $150 \mathrm{~Hz}$

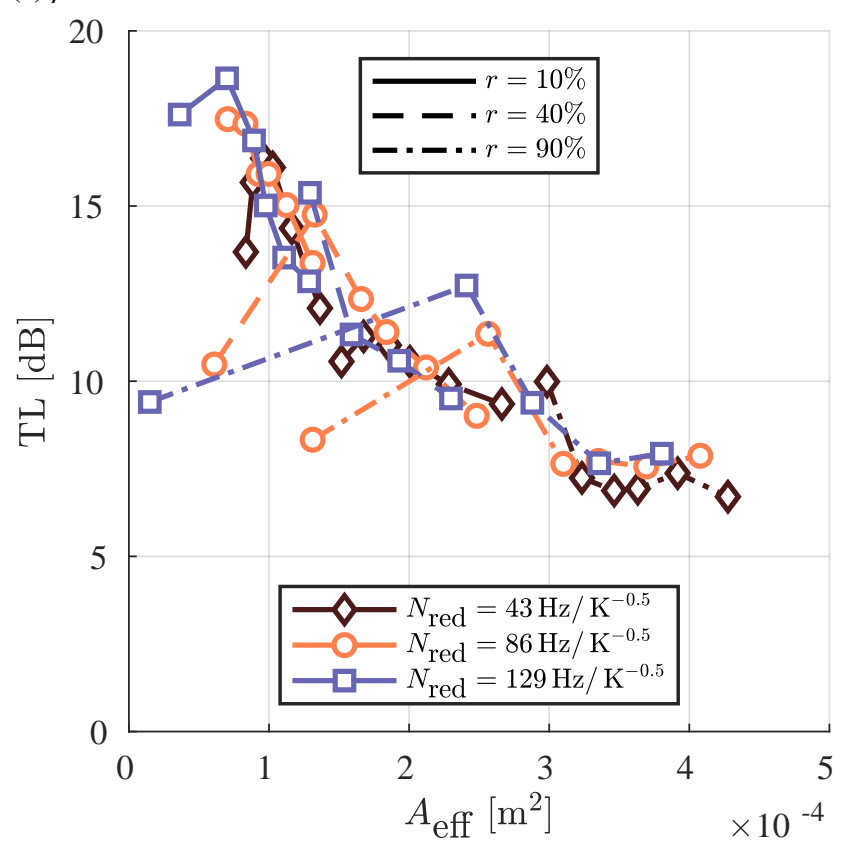

(b) $f=150 \mathrm{~Hz}$ to $300 \mathrm{~Hz}$

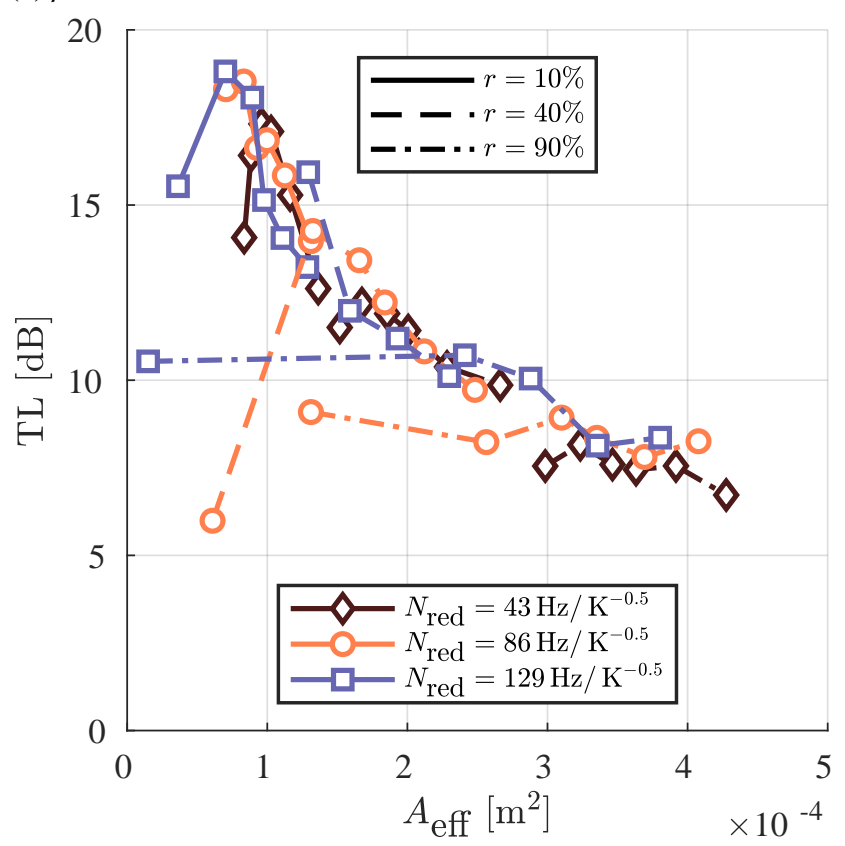

(d) $f=450 \mathrm{~Hz}$ to $600 \mathrm{~Hz}$

(c) $f=300 \mathrm{~Hz}$ to $450 \mathrm{~Hz}$

Figure 11. Transmission loss against the effective section of the turbine, averaged at different frequency bands 
In Figure 9 the evolution of the transmission loss against frequency is shown for a set of turbine operating points at different stator vanes positions and reduced speeds. Result from Figure 9a corresponds to a turbine point with a vanes position $10 \%$ and a reduced speed of $129 \mathrm{~Hz} \mathrm{~K}^{-0.5}$, Figure $9 \mathrm{~b}$ corresponds to a point of $40 \%$ and a reduced speed of $86 \mathrm{~Hz} \mathrm{~K}^{-0.5}$ and the result from Figure $9 \mathrm{c}$ corresponds to a vanes position of $90 \%$ and a reduced speed of $129 \mathrm{~Hz} \mathrm{~K}^{-0.5}$. At this point, some interesting observations can be made in relation to these results:

- The transmission loss decreases as the stator vanes open. The flow restriction produced by the stator is lower when the vanes are more open, which could explain this effect.

- In general, and for a given frequency, the transmission loss increases first as the pressure ratio increases, reaches a maximum value and then decreases again. The pressure ratio at which the maximum value is presented is close to the point where the slope of the effective section curve of Figure 8 starts to be constant. The specific pressure ratio at which this effect happens is also a function of the frequency.

The averaged transmission and reflection loss for the range of $0 \mathrm{~Hz}$ to $600 \mathrm{~Hz}$ has been computed and is shown in Figure 10 and Figure 11.

The trends shown in Figure 9 are better shown in Figure 10. Again, the transmission losses reach a maximum value at quite low expansion ratios. The main dependency is with the opening of the stator vanes, whereas the reduced speed effects are more noticeable at low expansion ratios. After the maximum transmission loss is reached, there is a small drop in transmission losses with growing frequencies.

Figure 11 shows the same results, but plotted against the effective area of the turbine. There is an obvious and clear effect of this effective area: the transmission losses grow as the effective area drops. However, the relationship between the effective area and the transmission losses is not bijective: other effects seems to be affecting the results. For a given effective area, the turbine efficiency might be different depending on the position of its vanes and its reduced speed. These changes in turbine adiabatic efficiency explain the rest of the changes in the turbine acoustic behaviour.

Figure 12 shows the evolution of the turbine adiabatic efficiency with the expansion ratio and the effective area. The transmission losses deviate more from a single bijective function of the effective area in points where the adiabatic efficiency is very far from design conditions, at very high blade speed ratios or low expansion ratios. From this, it is clear that it is necessary a model able to extrapolate accurately not only the mass flow but also the turbine adiabatic efficiency at far off-design conditions, such as the one used in this work[27] or, more recently, the losses model by Serrano et al.[44]. Also, specific experiments are needed to validate the results at these conditions.

As a conclusion, the position of the stator vanes mainly affecting the effective area, is the parameter that most affects the TL. The expansion ratio and reduced speed also change the effective area, although to a lesser extent. Also, the behaviour of the turbine is not exactly that of a simple connection between two one-dimensional elements of different section, as the effect of its efficiency is also visible in the results.

\section{Conclusions}

There is a clear time-scale separation between the very low frequency changes in the operating conditions of a radial turbine coupled to an engine (i.e., changes in engine load and rotational speed) and the instantaneous evolution of the pressure and temperature pulses due to the opening and closing of the exhaust valves. This way, the turbine behaviour can be approximated by that of an acoustic two-ports element superimposed to its average performance at each engine cycle. The acoustic two-ports element characteristics can be obtained from one-dimensional simulations and saved in a lookup table. These characteristics, in the form of an acoustic transfer matrix, can be interpolated each engine cycle in engine meanline models, with a very reduced computational cost. The generation of the lookup table, which is trivially parallelizable, can be performed in a preprocessing phase, and can be saved for later usage.

The accuracy of an acoustic matrix lookup table obtained with this procedure is directly related to the accuracy of the one-dimensional simulation it is based on. Good turbine map extrapolation capabilities are needed, as well as good acoustics-resolving one-dimensional computations. From the results obtained in this work, the number of points needed to get precise interpolations with the lookup table is fairly small, and should not be a big concern when applying this method.

The acoustic performance of a radial variable nozzle turbine seems to be mainly affected by its effective section. As the main parameter affecting the effective section is the position of its vanes, most of the changes in the acoustic performance are explained by it. The turbine expansion ratio is the second most important term affecting the effective section, whereas the reduced speed mainly affects the effective section at high blade speed ratios. In that off-design conditions, with little mass flow, the very low adiabatic efficiency of the turbine impacts the acoustic behaviour, producing a drift from that of a simple restriction between two ducts. This way, a reliable extrapolation of the adiabatic efficiency becomes mandatory when the sound and noise emissions of a radial turbine are to be computed at low engine loads and, thus, low expansion ratios.

It is worth mentioning that these kind of modelling only takes into account the passive acoustics of radial turbines. More work is needed if the active noise generation is needed, or if results are needed for frequencies outside of the plane wave range. Finally, specific experiments are needed to evaluate the sound and noise emissions and validate the model at extreme off-design conditions. 


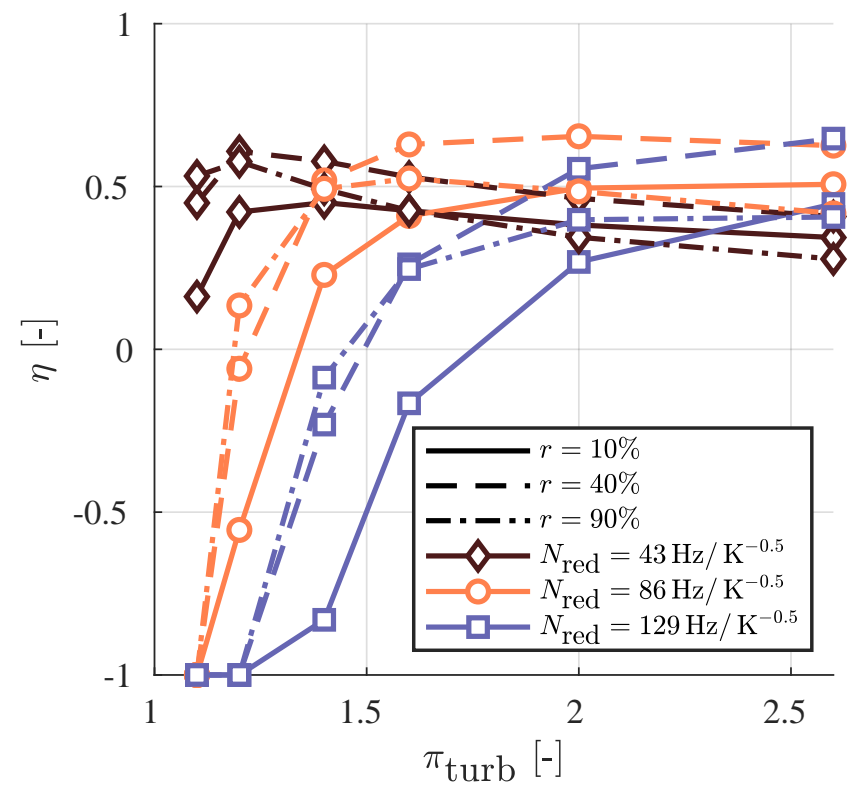

(a) Adiabatic efficiency against turbine expansion ratio

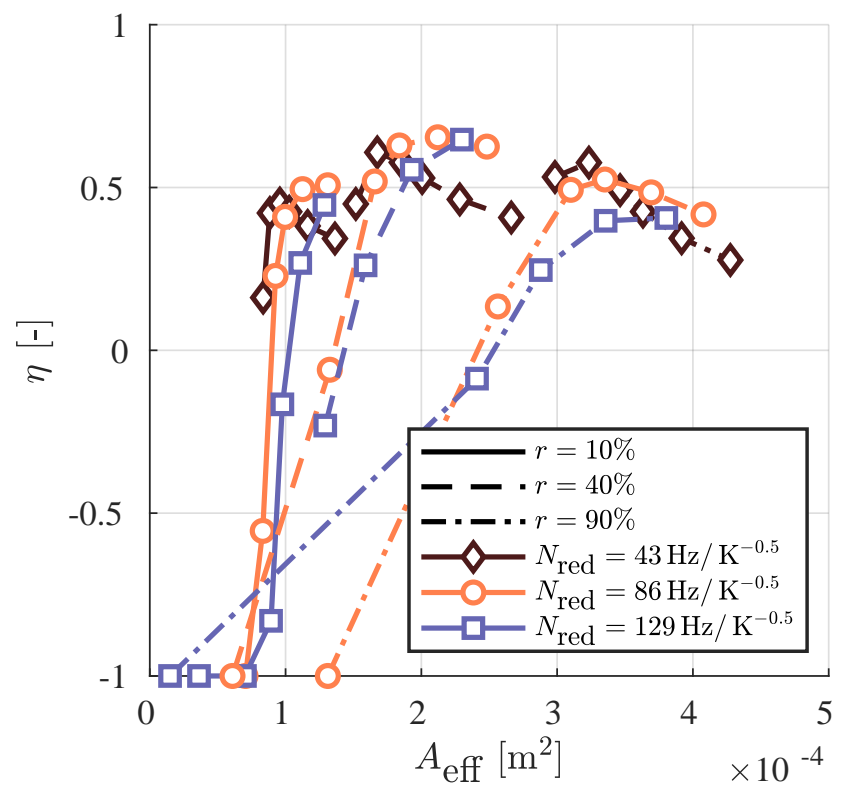

(b) Adiabatic efficiency against turbine effective area

Figure 12. Turbine efficiency against expansion ratio and effective section

\section{Acknowledgements}

The authors of this paper wish to thank M.A. Ortiz and R. Carrascosa for their invaluable work during the experimental setup and the campaign.

\section{Funding}

This work has been partially supported by the "Ayuda a Primeros Proyectos de Investigación" (PAID-06-18), Vicerrectorado de Investigación, Innovación y Transferencia de la Universitat Politècnica de València (UPV), València, Spain. Pablo Soler is partially supported through contract FPI-2017-S2-1428 of Programa de Apoyo para la Investigación y Desarrollo (PAID) of Universitat Politècnica de València.

\section{A Appendix A. Detailed model description}

The Euler classical governing equations for fluid dynamics are discretised across the set of $0 \mathrm{D}$ and 1D elements of the computational domain. These equations are shown in Equation 9 and Equation 10

$$
\begin{gathered}
\boldsymbol{w}=\left(\begin{array}{c}
\rho \\
\rho \cdot u \\
\rho \cdot e_{\mathrm{t}}
\end{array}\right)=\left(\begin{array}{c}
\rho \\
\rho \cdot u \\
\rho \cdot c_{\mathrm{v}} \cdot T+\rho \cdot u^{2} / 2
\end{array}\right) \\
\frac{\partial \boldsymbol{w}}{\partial t}=\frac{\partial}{\partial x}\left[\begin{array}{c}
\rho \cdot u \\
\rho \cdot u^{2}+p \\
\left.\rho \cdot u \cdot\left(c_{\mathrm{p}} \cdot T+u^{2} / 2\right)\right)
\end{array}\right]
\end{gathered}
$$

In these equations, $\boldsymbol{w}$ is the state vector, $\rho$ is the density, $u$ is the flow speed, $e_{t}$ is the specific total internal energy, $c_{\mathrm{V}}$ is the isochoric specific heat capacity, $T$ is the fluid temperature, $t$ is the time, $p$ is the gas pressure, and $c_{\mathrm{p}}$ is the isobaric specific heat capacity. The gases flowing through a turbine can be modelled as ideal gases, as in Equation 11.

$$
p=\rho \cdot R_{\text {gas }} \cdot T
$$

where $R$ is the gas constant. A Finite Volume Method is used to discretise Equation 9 and 10, obtaining Equation 12.

$$
\frac{\mathrm{d} \overline{\boldsymbol{w}}_{i}}{\mathrm{~d} t}=\frac{\left(A_{i-1, i} \cdot \boldsymbol{F}_{i-1, i}-A_{i, i+1} \cdot \boldsymbol{F}_{i, i+1}+\boldsymbol{C}_{i}\right)}{V_{i}}
$$

In Equation 12 $\overline{\boldsymbol{w}}_{\boldsymbol{i}}$ is the average value of the state vector inside cell $i, A_{i-i, i}$ is the surface area of the interface between cells $i-1$ and $i, \boldsymbol{F}_{i-1, i}$ is the flux vector between cells $i-1$ and $i, \boldsymbol{C}_{i}$ is the source terms vector that affects cell $i$, and the volume of the cell is represented by $V_{i}$. The source term vector takes into account effects such as heat fluxes or friction. In the simple case of a tapered pipe with no heat, friction or mass sources, it becomes Equation 13.

$$
\boldsymbol{C}_{i}=\left[\begin{array}{c}
0 \\
p_{i} \cdot\left(A_{i-1, i}-A_{i, i+1}\right) \\
0
\end{array}\right]
$$

To reconstruct the state vector, a second order Monotone Upstream-centered Scheme for Conservation Laws (MUSCL, [45]) is used. To maintain total-variationdiminishing properties, the linear extrapolation of the state vector to the cell boundaries is limited using the monotonised central slope limiter by van Leer. Finally, the fluxes are computed using the Harten-Lax-van Leer-Contact approximate Riemann solver as described in [46].

Equation 12 is solved each time-step using Heun's method, an explicit, second-order time-integration scheme. The time-step is chosen at each iteration following the Courant-Friedrichs-Lewy condition (CFL, [47]), as in Equation 14

$$
\Delta t=\left.v \cdot \frac{\Delta x}{\lambda}\right|_{\min }=\left.v \cdot \frac{\Delta x}{|u|+|a|}\right|_{\min }
$$

where $v$ is the CFL number, the size of each cell is represented by $\Delta x$ and $\lambda$ is an eigenvalue of the system. 
The maximum eigenvalues of the system are approximated by $|u|+|a|, a$ being the speed of sound. The subscript min represents the minimum value.

\section{Nomenclature}

\section{Abbreviations}

$\begin{array}{ll}\text { OD } & \text { Zero-dimensional } \\ \text { ID } & \text { One-dimensional } \\ \text { BF } & \text { Beamforming array } \\ \text { IATM } & \text { Interpolated acoustic transfer matrix } \\ \text { C } & \text { Compressor } \\ \text { CFD } & \text { Computational fluid dynamics } \\ \text { CFL } & \text { Courant-Friedrichs-Levvy } \\ \text { ICS } & \text { Independent cooling system } \\ \text { ILS } & \text { Independent lubrication system } \\ \text { PID } & \text { Proportional-integral-derivative controller } \\ \text { PSD } & \text { Power spectral density } \\ \text { RMSE } & \text { Root-mean-square error } \\ \text { RTD } & \text { Resistance temperature detector } \\ \text { RV } & \text { Rotating valve } \\ \text { T } & \text { Turbine } \\ \text { TL } & \text { Transmission loss } \\ \text { VGT } & \text { Variable geometry turbine }\end{array}$

Roman letters

$\begin{array}{ll}A & \text { Area } \\ a & \text { Speed of sound, effective area fitting } \\ & \text { parameter } \\ b & \text { Effective area fitting parameter } \\ \boldsymbol{C} & \text { Source terms vector } \\ c & \text { Specific heat capacity, effective area fitting } \\ & \text { parameter } \\ D & \text { Diameter } \\ d & \text { Effective area fitting parameter } \\ e & \text { Specific internal energy, efficiency fitting } \\ & \text { parameter } \\ \boldsymbol{F} & \text { Flux vector } \\ f, g, h, i, j & \text { Efficiency fitting parameters } \\ \dot{m} & \text { Mass flow rate } \\ N & \text { Rotational speed } \\ P & \text { Pressure, frequency domain } \\ p & \text { Pressure } \\ R & \text { Reflection coefficient, gas constant } \\ r & \text { Vanes position } \\ T & \text { Temperature, transmission coefficient } \\ t & \text { Time } \\ u & \text { Flow speed } \\ V & \text { Cell volume } \\ \boldsymbol{w} & \text { State vector } \\ x & \text { Axial coordinate } \\ z & \text { Efficiency correction term }\end{array}$

Greek letters

$\begin{array}{ll}\Delta & \text { Interval, distance } \\ \gamma & \text { Specific heat capacities ratio }\end{array}$

$\begin{array}{ll}\lambda & \text { Eigenvalue } \\ \nu & \text { CFL number } \\ \pi & \text { Pressure ratio } \\ \rho & \text { Density } \\ \sigma & \text { Blade speed ratio }\end{array}$

Subscripts

$0 \quad$ Domain inlet section

1 Turbine inlet section

2 Volute lateral window section

2' Stator nozzles throat section

3 Rotor inlet section

4 Rotor outlet section

5 Turbine outlet section

6 Domain outlet section

gas Gas

in Turbine inlet

out Turbine outlet

eff Effective

$i \quad$ Cell number

$\mathrm{p} \quad$ Isobaric

red Reduced

t Total conditions

turb Turbine

v Isochoric

\begin{tabular}{ll}
\multicolumn{2}{l}{ Superscripts } \\
+ & Forward travelling wave \\
- & Backwards travelling wave \\
lower & Lower value \\
upper & Upper value
\end{tabular}

Overbar

- Average value

\section{References}

1. Rämmal $\mathrm{H}$ and Åbom M. Acoustics of turbochargers. In $S A E$ 2007 Noise and Vibration Conference and Exhibition. SAE International. DOI:10.4271/2007-01-2205.

2. Broatch A, Galindo J, Navarro R et al. Methodology for experimental validation of a CFD model for predicting noise generation in centrifugal compressors. International Journal of Heat and Fluid Flow 2014; 50: 134 - 144. DOI:10.1016/j. ijheatfluidflow.2014.06.006.

3. Galindo J, Tiseira A, Navarro $R$ et al. Effect of the inlet geometry on performance, surge margin and noise emission of an automotive turbocharger compressor. Applied Thermal Engineering 2017; 110: 875-882. DOI:10.1016/j. applthermaleng.2016.08.099.

4. Broatch A, Margot X, García-Tíscar J et al. Impact of simple surge-enhancing inlet geometries on the acoustic behavior of a turbocompressor. International Journal of Engine Research 2018; DOI:10.1177/1468087418784125.

5. Sharma S, Broatch A, García-Tíscar J et al. Acoustic characteristics of a ported shroud turbocompressor operating at design conditions. International Journal of Engine Research 2018; DOI:10.1177/1468087418814635.

6. Peat K, Torregrosa A, Broatch A et al. An investigation into the passive acoustic effect of the turbine in an automotive 
turbocharger. Journal of Sound and Vibration 2006; 295: 6075. DOI:10.1016/j.jsv.2005.11.033.

7. Torregrosa A, Galindo J, Serrano JR et al. A procedure for the unsteady characterization of turbochargers in reciprocating internal combustion engines. In $\mathrm{Xu} \mathrm{J}, \mathrm{Wu} \mathrm{Y}$, Zhang Y et al. (eds.) Fluid Machinery and Fluid Mechanics. Berlin, Heidelberg: Springer Berlin Heidelberg, pp. 72-79. DOI: 10.1007/978-3-540-89749-1_10.

8. Torregrosa AJ, Broatch A, Navarro R et al. Acoustic characterization of automotive turbocompressors. International Journal of Engine Research 2015; 16(1): 31-37. DOI:10.1177/ 1468087414562866.

9. Kabral R, El Nemr YA, Ludwig C et al. Experimental acoustic characterization of automotive twin-scroll turbine. In 12 th European Conference on Turbomachinery Fluid dynamics \& Thermodynamics. European Turbomachinery Society. DOI: 10.29008/ETC2017-363.

10. Serrano J, Arnau F, García-Cuevas LM et al. An Experimental Method to Test Twin and Double Entry Automotive Turbines in Realistic Engine Pulse Conditions. In WCX SAE World Congress Experience. DOI:10.4271/2019-01-0319. SAE Technical Paper 2019-01-0319.

11. Broatch A, Galindo J, Navarro R et al. Simulations and measurements of automotive turbocharger compressor whoosh noise. Engineering Applications of Computational Fluid Mechanics 2015; 9: 12-20. DOI:10.1080/19942060.2015. 1004788.

12. Broatch A, Galindo J, Navarro $R$ et al. Numerical and experimental analysis of automotive turbocharger compressor aeroacoustics at different operating conditions. International Journal of Heat and Fluid Flow 2016; 61: 245 - 255. DOI: 10.1016/j.ijheatfluidflow.2016.04.003.

13. Marsan A and Moreau S. Analysis of the flow structure in a radial turbine. In 11th European Conference on Turbomachinery Fluid Dynamics and Thermodynamics, ETC 2015. Madrid, Spain.

14. Wallace FJ and Adgey J. Paper 1: Theoretical assessment of the non-steady flow performance of inward radial flow turbines. Proceedings of the Institution of Mechanical Engineers, Conference Proceedings 1967; 182(8): 22-36. DOI: 10.1243/PIME \_CONF\_1967\182\211\02.

15. Winterbone $\mathrm{D}$ and Pearson R. Turbocharger turbine performance under unsteady flow-a review of experimental results and proposed models. Inst Mech Eng Semin, paper C55403198 1998;

16. Hohenberg KG, Newton PJ, Martinez-Botas RF et al. Development and experimental validation of a low order turbine model under highly pulsating flow. In Turbo Expo: Power for Land, Sea, and Air, Volume 2C: Turbomachinery. ASME, p. V02CT44A023. DOI:10.1115/GT2017-63983.

17. Ding Z, Zhuge $\mathrm{W}$, Zhang $\mathrm{Y}$ et al. A one-dimensional unsteady performance model for turbocharger turbines. Energy 2017; DOI:10.1016/j.energy.2017.04.154.

18. Piscaglia F, Onorati A, Marelli S et al. A detailed one-dimensional model to predict the unsteady behavior of turbocharger turbines for internal combustion engine applications. International Journal of Engine Research 2019, 20(3): 327-349. DOI:10.1177/1468087417752525.

19. Galindo J, Fajardo P, Navarro R et al. Characterization of a radial turbocharger turbine in pulsating flow by means of CFD and its application to engine modeling. Applied Energy 2013;
103(0): 116 - 127. DOI:10.1016/j.apenergy.2012.09.013.

20. Costall AW, McDavid RM, Martínez-Botas RF et al. Pulse performance modelling of a twin-entry turbocharger turbine under full unequal admission. In Proceedings of ASME Turbo Expo 2009. ASME. DOI:10.1115/1.4000566. 2009.

21. Chiong MS, Rajoo S, Romagnoli A et al. Unsteady performance prediction of a single entry mixed flow turbine using 1-D gas dynamic code extended with meanline model. In Proceedings of the ASME Turbo Expo, volume 5. ASME, pp. 781-795. DOI:10.1115/GT2012-69176.

22. Galindo J, Tiseira A, Fajardo $P$ et al. Development and validation of a radial variable geometry turbine model for transient pulsating flow applications. Energy Conversion and Management 2014; 85: 190 - 203. DOI:10.1016/j.enconman. 2014.05.072.

23. Avola C, Copeland C, Romagnoli A et al. Attempt to correlate simulations and measurements of turbine performance under pulsating flows for automotive turbochargers. Proceedings of the Institution of Mechanical Engineers, Part D: Journal of Automobile Engineering 2019; 233(2): 174-187. DOI: 10.1177/0954407017739123.

24. Veloso R, Elnemr Y, Reich FM et al. Simulation of sound transmission through automotive turbochargers. In 7th International Styrian Noise, Vibration \& Harshness Congress: The European Automotive Noise Conference. SAE International. DOI:10.4271/2012-01-1560.

25. Galindo J, Climent $\mathrm{H}$, Tiseira A et al. Effect of the numerical scheme resolution on quasi-2D simulation of an automotive radial turbine under highly pulsating flow. Journal of Computational and Applied Mathematics 2016; 291: 112126. DOI:10.1016/j.cam.2015.02.025.

26. Galindo J, Arnau FJ, García-Cuevas LM et al. Experimental validation of a quasi-two-dimensional radial turbine model. International Journal of Engine Research 2018; DOI:10.1177/ 1468087418788502.

27. Serrano JR, Arnau FJ, García-Cuevas LM et al. Development and validation of a radial turbine efficiency and mass flow model at design and off-design conditions. Energy Conversion and Management 2016; 128: 281 - 293. DOI:10.1016/j. enconman.2016.09.032.

28. Galindo J, Tiseira A, Navarro R et al. Compressor Efficiency Extrapolation for 0D-1D Engine Simulations. In SAE 2016 World Congress and Exhibition. SAE International. DOI: 10.4271/2016-01-0554. SAE Technical Paper 2016-01-0554.

29. Galindo J, Navarro R, García-Cuevas LM et al. A zonal approach for estimating pressure ratio at compressor extreme off-design conditions. International Journal of Engine Research 2019; 20(4): 393-404. DOI:10.1177/ 1468087418754899.

30. Payri F, Olmeda P, Arnau FJ et al. External heat losses in small turbochargers: Model and experiments. Energy 2014; 71: 534 - 546. DOI:10.1016/j.energy.2014.04.096.

31. Serrano JR, Olmeda P, Arnau FJ et al. Turbocharger heat transfer and mechanical losses influence in predicting engines performance by using one-dimensional simulation codes. Energy 2015; 86: 204 - 218. DOI:10.1016/j.energy. 2015.03.130.

32. Gil A, Tiseira A, García-Cuevas LM et al. Fast threedimensional heat transfer model for computing internal temperatures in the bearing housing of automotive turbochargers. International Journal of Engine Research 2018; DOI:10.1177/ 
1468087418804949.

33. Serrano JR, Olmeda P, Tiseira A et al. Theoretical and experimental study of mechanical losses in automotive turbochargers. Energy 2013; 55(0): 888 - 898. DOI:10.1016/j. energy.2013.04.042.

34. Pinero G, Vergara L, Desantes JM et al. Estimation of velocity fluctuation in internal combustion engine exhaust systems through beamforming techniques. Measurement Science and Technology 2000; 11(11): 1585. DOI:10.1088/0957-0233/11/ 11/307.

35. Supercharger testing standard. SAE J1723, Society of Automotive Engineers, 1995.

36. Turbocharger gas stand test code. SAE J1826, Society of Automotive Engineers, 1995.

37. CMT - Motores Térmicos, Universitat Politècnica de València. OpenWAM, 2016. URL http: // www . openwam.org/

38. Galindo J, Serrano JR, Arnau FJ et al. Description of a SemiIndependent Time Discretization Methodology for a OneDimensional Gas Dynamics Model. Journal of Engineering for Gas Turbines and Power 2009; 131(3): 034504. DOI: 10.1115/1.2983015.

39. Serrano JR, Arnau FJ, Dolz V et al. A model of turbocharger radial turbines appropriate to be used in zero- and onedimensional gas dynamics codes for internal combustion engines modelling. Energy Conversion and Management 2008; 49(12): 3729 - 3745. DOI:10.1016/j.enconman.2008.06.031.

40. Serrano JR, Tiseira A, García-Cuevas LM et al. Radial turbine performance measurement under extreme off-design conditions. Energy 2017; 125: 72-84. DOI:10.1016/j.energy. 2017.02.118.

41. Welch $P$. The use of fast fourier transform for the estimation of power spectra: A method based on time averaging over short, modified periodograms. IEEE Transactions on Audio Electroacoustics 1967; 15: 70-73. DOI:10.1109/TAU.1967. 1161901.

42. Zhu Z, Midlam-Mohler S and Canova M. Development of physics-based three-way catalytic converter model for realtime distributed temperature prediction using proper orthogonal decomposition and collocation. International Journal of Engine Research 2019; DOI:10.1177/1468087419876127.

43. Gordon D, Wouters C, Wick M et al. Development and experimental validation of a real-time capable field programmable gate array-based gas exchange model for negative valve overlap. International Journal of Engine Research 2019; DOI:10.1177/1468087418788491.

44. Serrano JR, Arnau FJ, García-Cuevas LM et al. An innovative losses model for efficiency map fitting of vaneless and variable vaned radial turbines extrapolating towards extreme off-design conditions. Energy 2019; 180: 626 - 639. DOI:10.1016/j. energy.2019.05.062.

45. van Leer B. Towards the Ultimate Conservation Difference Scheme. II. Monotonicity and Conservation Combined in a Second-Order Scheme. Journal of Computational Physics 1974; 14: 361. DOI:10.1016/0021-9991(74)90019-9.

46. Toro E, Spruce M and Speares W. Restoration of the contact surface in the HLL-Riemann solver. Shock Waves 1994; 4(1): 25-34. DOI:10.1007/BF01414629.

47. Courant R, Friedrichs $K$ and Lewy H. Über die partiellen differenzengleichungen der mathematischen physik. Mathematische Annalen 1928; 100(1): 32-74. DOI:10.1007/ bf01448839. 